\title{
An in situ XAS study of ferric iron hydrolysis and precipitation in the presence of perchlorate, nitrate, chloride and sulfate
}

Richard N. Collins $^{\mathrm{a}, *}$, Kevin M. Rosso ${ }^{\mathrm{b}}$, Andrew L. Rose ${ }^{\mathrm{c}}$, Chris J. Glover ${ }^{\mathrm{d}}$ and T. David Waite ${ }^{\mathrm{a}}$

${ }^{a}$ UNSW Water Research Centre, School of Civil and Environmental Engineering, UNSW Australia, Sydney, NSW 2052, Australia.

${ }^{b}$ Environmental Molecular Sciences Laboratory, Pacific Northwest National Laboratory, Richland, WA 99336, USA.

c Southern Cross Geoscience, Southern Cross University, PO Box 157, Lismore, NSW 2480, Australia.

${ }^{d}$ X-ray Absorption Spectroscopy Beamline, Australian Synchrotron Company Ltd, 800 Blackburn Rd, Clayton, VIC 3168, Australia.

Revised and re-submitted to Geochimica et Cosmochimica Acta

$21^{\text {st }}$ January 2016

* Corresponding author, Tel: +61 29385 5082, Email: richard.collins@unsw.edu.au, Address: UNSW Water Research Centre, School of Civil and Environmental Engineering, UNSW Australia, Sydney, NSW 2052, Australia. 


\section{Abstract}

2 Using a novel combination of in situ potentiometric experiments and quick-scanning XAS we 3 present $\mathrm{Fe}$ K-edge XAS spectra (to $\mathrm{k}=12 \AA^{-1}$ ) during $\mathrm{Fe}^{\mathrm{III}}$ hydrolysis and precipitation in $0.33 \mathrm{M}$ $4 \mathrm{Fe}\left(\mathrm{ClO}_{4}\right)_{3}, \mathrm{Fe}\left(\mathrm{NO}_{3}\right)_{3}, \mathrm{FeCl}_{3}$ and $\mathrm{Fe}_{2}\left(\mathrm{SO}_{4}\right)_{3}$ solutions up to $\mathrm{pH}$ 4.8. Edge-sharing $\mathrm{Fe}^{\mathrm{III}}$ polymers 5 appeared almost immediately upon hydrolysis with strong evidence for a $\mu$-oxo dimer species 6 forming in the $\mathrm{Fe}\left(\mathrm{ClO}_{4}\right)_{3}, \mathrm{Fe}\left(\mathrm{NO}_{3}\right)_{3}$ and $\mathrm{FeCl}_{3}$ solutions. The effects of $\mathrm{SO}_{4}$ on hydrolysis and 7 polymerization pathways included inhibition of both the formation of the $\mu$-oxo dimer and double 8 corner $\mathrm{Fe}^{\mathrm{III}}$ bonding, ultimately resulting in the precipitation of schwertmannite. As such, under these 9 experimental conditions, double corner $\mathrm{Fe}^{\mathrm{III}}$ bonding appears to be critical to the formation of 10 ferrihydrite. The spectral trends indicated that the decomposition/transformation of the dimer was 11 sudden and broadly coincident with shortening average $\mathrm{Fe}-\mathrm{O}$ bond distances, increased $\mathrm{Fe}$ neighbors 12 at $\sim 3.43 \AA$ and a pre-edge energy transformation suggestive of decreased ligand field strength as well 13 as increasing proportions of tetrahedral $\mathrm{Fe}^{\mathrm{III}}$. This result suggests that the incorporation of 14 tetrahedral $\mathrm{Fe}^{\mathrm{III}}$ into ferrihydrite occurs only at the latter stages of extended polymerization. 


\section{INTRODUCTION}

16 Due to its unique (redox) chemistry, iron is arguably the most important transition metal to life on earth. Although the aqueous chemistry of ferric iron $\left(\mathrm{Fe}^{\mathrm{III}}\right)$ has been intensively studied for over 50 years, many aspects relating to hydrolysis and precipitation pathways (even to ubiquitous solid phases such as ferrihydrite) remain unresolved. Ferrihydrite is the natural nano-crystalline $\mathrm{Fe}^{\mathrm{III}}$ oxyhydroxide that most often controls $\mathrm{Fe}^{\mathrm{III}}$ solubility during forced hydrolysis (Cornell and Schwertmann, 2003). Its structure has been debated since the first detailed structural models of the mineral were proposed in 1967 (Harrison et al., 1967; Towe and Bradley, 1967) with much of the debate concerning the presence (or absence) of tetrahedrally-coordinated Fe ${ }^{\mathrm{III}}$ (Cardile, 1988; Combes et al., 1989; Cowley et al., 2000; De Grave et al., 2005; Drits et al., 1993; Eggleton and Fitzpatrick, 1988, 1990; Gray, 1971; Harrison et al., 1967; Hiemstra and van Riemsdijk, 2009; Janney et al., 2000; Magini, 1977; Manceau, 2009, 2010; Manceau et al., 1990; Manceau and Drits, 1993; Manceau and Gates, 1997; Michel et al., 2010; Michel et al., 2007a; Michel et al., 2007b; Murad, 1988; Murad and Schwertmann, 1980; Pan et al., 2010; Pankhurst and Pollard, 1992; Rancourt and Meunier, 2008; Waychunas et al., 1996; Waychunas et al., 1993; Zhao et al., 1994; Zhao et al., 1993). Increasingly, evidence from a range of techniques has converged to support the presence of a tetrahedral component in ferrihydrite (Guyodo et al., 2012; Harrington et al., 2011; Maillot et al., 2011; Michel et al., 2007a; Xu et al., 2011). Nevertheless, uncertainty remains with regard to the forms of aqueous $\mathrm{Fe}^{\mathrm{III}}$ hydrolysis and inorganically complexed species that arise prior to ferrihydrite precipitation and how tetrahedral $\mathrm{Fe}^{\mathrm{III}}$ is structurally incorporated (Combes et al., 1989; de Abreu et al., 2006; Kubicki, 2001; Lopes et al., 2002; Magini and Caminiti, 1977; Martin et al., 1998; Mulay and Selwood, 1955; Perera and Hefter, 2003; Pham et al., 2006; Schwertmann et al., 1999; Yang et al., 2013; Zhu et al., 2016; Zhu et al., 2012; Zhu et al., 2013).

Iron K-edge X-ray absorption spectroscopy (XAS) has been one of the most popular analytical techniques to examine ferric iron complexation, hydrolysis and precipitation pathways since it is element specific and can be used to analyze both liquid and solid phases (Bottero et al., 1994; Combes et al., 1989; Doelsch et al., 2000; Drits et al., 1993; Maillot et al., 2011; Manceau and Drits, 1993; Manceau and Gates, 1997; Mikutta, 2011; Pokrovski et al., 2003; Rose et al., 1996; Rose et al., 1997; Waychunas et al., 1993; Westre et al., 1997; Zhu et al., 2016; Zhu et al., 2012; Zhu et al., 2013). Here we report on the application of quick-scanning XAS, which allowed for the collection of spectral data to $\sim 1000 \mathrm{eV}$ above the Fe K-edge in 22 seconds (Electronic Annex, Figure A1), thereby enabling the procurement of spectral data from in situ potentiometric experiments undertaken with the purpose of improving our understanding of the hydrolysis and precipitation pathways of $\mathrm{Fe}^{\mathrm{III}}$. These experiments have been undertaken in the presence of four inorganic anions 
49 to compare how they may affect polymerization pathways as a result of strong complexation (e.g. 50 between $\mathrm{Cl}$ and $\mathrm{SO}_{4}$ ) relevant to oceanic, estuarine and acid sulfate environments (Rose and Waite, 51 2003; Zhu et al., 2012). Quick-scanning XAS has previously proven useful in studying the temporal

52 speciation of $\mathrm{Fe}^{\mathrm{III}}$ in partially-neutralized ferric nitrate solutions (Zhu et al., 2016; Zhu et al., 2013) 53 as well as solid-state transformations of ferrihydrite to schwertmannite (Zhu et al., 2012) at acidic $\mathrm{pH}$ 54 values. Thermodynamic equilibrium speciation and density functional theory (DFT) electronic structure calculations as well as reference to the literature have also been undertaken to aid interpretation of the Fe K-edge XAS data.

\section{MATERIALS AND METHODS}

\subsection{Thermodynamic equilibrium speciation calculations}

The dominant aqueous (and solid) $\mathrm{Fe}^{\mathrm{III}}$ species expected to be present, at thermodynamic equilibrium, over the range of experimental conditions used in this study were determined using the computer speciation program Visual MINTEQ, version 3.1. The specific ion interaction model (SIT) was used for activity corrections, and the stability constants of the aqueous species and solubility products of ferrihydrite and schwertmannite used for these calculations are listed in Table A1.

\subsection{Density functional theory (DFT) computations}

68 Molecular orbital theory first principles calculations were performed with NWChem (Valiev et al., 69 2010) to determine the total energies and optimized structures of the most stable aqueous species of $70 \mathrm{Fe}^{\mathrm{III}}$ that could occur during the potentiometric experiments. Ground-state geometry optimizations were undertaken using the open-shell Kohn-Sham DFT formalism and the B3LYP hybrid exchangecorrelation functional (Becke, 1993). No symmetry restrictions were imposed on the geometry optimizations. Ahlrichs pVDZ was used as the Fe atom basis set and the 6-31G** basis set was used for $\mathrm{H}, \mathrm{N}, \mathrm{O}, \mathrm{S}$ and $\mathrm{Cl}$, which were obtained from the EMSL Basis Set library (Feller, 1996; Schuchardt et al., 2007). Concatenated fragment molecular orbitals were used to precondition the initial guess wavefunction with the desired initial spin structure, however, other than to fix the total spin multiplicity, no spin restrictions were imposed. Optimizations were first performed on the species in vacuo and these structures and converged wavefunctions were then used as a starting guess for optimizations performed with the COSMO dielectric continuum solvation model thereby enabling inclusion of the screening effects of surrounding bulk water in the final calculated structure and total energy (Klamt and Schuurmann, 1993). Vibrational frequencies of the optimized structures were then obtained for the solvated aqueous species, and the thermochemical contributions to 
83 enthalpy and entropy were computed at $298.15 \mathrm{~K}$ and $1 \mathrm{~atm}$ to obtain the total Gibbs free energy at 84 this standard condition. As discussed in Martin et al. (1998), this standard state, conventional in molecular orbital theory codes, includes a small error with respect to the condensed solution phase that must be corrected in absolute total energies of aqueous species, but cancels through total energy differences of species, such as exclusively used here. Only the results obtained for the optimized species in the aqueous phase are reported.

\subsection{Solution/suspension conditions}

91 Solutions (total $\left[\mathrm{Fe}^{\mathrm{III}}\right]=0.33 \mathrm{M}$ ) made from $\mathrm{Fe}\left(\mathrm{ClO}_{4}\right)_{3} \cdot \mathrm{H}_{2} \mathrm{O}, \mathrm{Fe}_{2}\left(\mathrm{SO}_{4}\right)_{3} \cdot x \mathrm{H}_{2} \mathrm{O}, \mathrm{FeCl}_{3}$ and $92 \mathrm{Fe}\left(\mathrm{NO}_{3}\right)_{3} .9 \mathrm{H}_{2} \mathrm{O}$ (Sigma-Aldrich, Australia) dissolved in high-purity (18.2 M $\Omega . c m$ resistivity) water 93 were potentiometrically titrated from their starting $\mathrm{pH}$ through to precipitation by the dropwise 94 addition of $2 \mathrm{M} \mathrm{KOH}$ using a syringe pump. The solutions/suspensions were rapidly mixed using a 95 magnetic stirrer and $\mathrm{pH}$ was measured in the solutions/suspensions using a $\mathrm{pH}$ probe calibrated using NIST-traceable buffers on the NBS scale. Throughout the experiments, sufficient KOH was added to increase $\mathrm{pH}$ through $\sim 0.1 \mathrm{pH}$ increments until it was evident that complete hydrolysis (and precipitation) of $\mathrm{Fe}^{\mathrm{III}}$ had occurred (i.e., the solution provided no $\mathrm{pH}$ buffering to further $\mathrm{KOH}$ addition). The potentiometric experiments were conducted in situ at the XAS beamline of the Australian Synchrotron, Melbourne, Australia. The solution/suspensions were continuously (re)circulated through a $1.5 \mathrm{~mm}$ I.D. kapton tube using a peristaltic pump. After $\mathrm{pH}$ stabilization at each $\mathrm{pH}$ increment ( $\sim 0.1 \mathrm{pH}$ units), two to four transmission XAS spectra were collected through the kapton tube. The addition of $\mathrm{KOH}$, and $\mathrm{pH}$ measurements, were facilitated remotely from outside the hutch and all experiments were completed within approximately 2.5 hours.

The high ionic strength of the solutions/suspensions used in these experiments required correction of measured $\mathrm{pH}$ values (on the National Bureau of Standards, NBS, scale) to obtain $\mathrm{pH}$ values on the free hydrogen ion scale, i.e. $\mathrm{pH}_{\mathrm{F}}$. This correction was achieved by the following methodology. A $\mathrm{pH}$ titration of a solution containing $0.9 \mathrm{M}$ of the sodium salt (e.g. $\mathrm{NaCl}$ ) and $0.1 \mathrm{M}$ of the acid (e.g. $\mathrm{HCl}$ ) or, in the case of sulfate, $0.45 \mathrm{M} \mathrm{Na}_{2} \mathrm{SO}_{4}+0.05 \mathrm{M} \mathrm{H}_{2} \mathrm{SO}_{4}$, with $1 \mathrm{M} \mathrm{NaOH}$ was undertaken using a Metrohm Titrando autotitrator equipped with the same $\mathrm{pH}$ probe as used for the in situ experiments at the Australian Synchrotron. From the titration data, theoretical pH values were derived based on the volume of $1 \mathrm{M} \mathrm{NaOH}$ added and the sum of squares of residuals (SSR) were calculated with comparison to the measured $\mathrm{pH}$ values. Microsoft Excel's solver was then used to minimize the SSR by adjusting the starting concentration of acid. This step was important in order to obtain a linear relationship between measured and theoretical $\mathrm{pH}$ values (as expected) since the 
116 shape of the titration curve is very sensitive to small errors in the starting acid concentration. The

117 calculated correction parameters $\varepsilon$ and $s$ were then used to correct the measured $\mathrm{pH}$ values by 118 linearly relating the measured $\mathrm{pH}(\mathrm{NBS})$ with the theoretical $\mathrm{pH}_{\mathrm{F}}$ per the equation $\mathrm{pH}_{\mathrm{F}}=\varepsilon+$ $119 s^{*} \mathrm{pH}(\mathrm{NBS})$ (Table A2). Data are also presented as a function of the molar hydrolysis ratio $(\mathrm{OH}: \mathrm{Fe})$ 120 which is the ratio of the total molar quantity of base added to the molar quantity of $\mathrm{Fe}^{\mathrm{III}}$ present in the 121 solution/suspension.

\section{2.4. Additional solid- and solution phase characterization measurements}

124 At the completion of the potentiometric experiments all of the resulting suspensions were 125 centrifuged, to aid phase separation, and the solid phases were washed and centrifuged a further three 126 times with high purity water. A subsample of the washed suspensions was analyzed by FTIR-ATR.

127 The suspension was dried onto the ATR with $\mathrm{N}_{2(\mathrm{~g})}$ and the spectrum was acquired at a resolution of 2 $128 \mathrm{~cm}^{-1}$ with a Perkin Elmer Frontier FTIR spectrometer. Default parameters were used to baseline 129 correct the spectrum. The remaining solid phases were subsequently frozen and freeze-dried. 130 Powder X-ray diffractograms were obtained from 10 to 85 degrees (20) with a PANalytical Xpert 131 XRD using a $\mathrm{Cu}-\mathrm{K} \alpha \mathrm{X}$-ray source and peak identification was performed using the software 132 programme HighScore v4.1 (PANalytical).

133 Additional UV-vis spectra were recorded of the solutions before the addition of any base (i.e. OH:Fe $134=0$ ), over a 1-cm path length, using a Cary 50 UV-Vis spectrophotometer (Agilent Technologies, 135 Santa Clara, CA, USA).

\section{2.5. X-ray absorption spectroscopy measurements}

138 X-ray absorption spectroscopy measurements across the Fe K-edge were undertaken at the 139 Australian Synchrotron on the XAS beamline using an 'on-the-fly' approach which allowed the 140 collection of transmission EXAFS spectra to $\sim 1000 \mathrm{eV}\left(\sim 16 \AA^{-1}\right.$ in $\mathrm{k}$ space $)$ above the edge in 22 141 seconds. Comparison of 'on-the-fly' spectra obtained for Fe foil with that obtained with a traditional 14245 minute step-by-step scan demonstrated no degradation in the quality of EXAFS data obtained 143 (EA, Figure A1). The XAS beamline (and synchrotron) operational conditions were identical to 144 those previously described (Boland et al., 2013) and the hutch was temperature-controlled to 20 \pm 1 $145{ }^{\circ} \mathrm{C}$. 
148 Processing of the XAS data was performed using the standard features of ATHENA (Ravel and 149 Newville, 2005) including alignment and merging of multiple spectra and energy calibration to 150 elemental Fe. All spectra were treated identically in terms of normalization and background removal. 151 The $\mathrm{E}_{0}$ value was fixed at $7125.935 \mathrm{eV}$, the first inflection point of the $1^{\text {st }}$ derivative data for the 152 initial spectrum collected on the solutions, for all spectra. The Autobk algorithm was used for 153 background removal and an Rbkg value of 0.97 was applied to optimize high frequency background 154 removal. ARTEMIS (Ravel and Newville, 2005) was used to generate theoretical phase and 155 amplitude functions for single and multiple scattering pathways of $\mathrm{Fe}-\mathrm{O}$ from monomeric $\mathrm{Fe}\left(\mathrm{H}_{2} \mathrm{O}\right)\left({ }_{6}\right.$ $156{ }_{\mathrm{x}}(\mathrm{OH})_{(\mathrm{x})}$ in octahedral or tetrahedral geometry. Single scattering pathways of Fe-Fe were generated 157 from the crystallographic data of goethite (Gualtieri and Venturelli, 1999). EXAFS modelling of all 158 coordination shells was undertaken simultaneously from 0.97 - $3.8 \AA$ in R space, phase uncorrected, 159 on forward Fourier-transformed $\mathrm{k}^{3}$-weighted $\chi(\mathrm{k})$ data from $2-12 \AA^{-1}$ (providing a distance 160 resolution of $\sim 0.13 \AA$ ). The amplitude reduction factor $\left(\mathrm{S}_{\mathrm{o}}{ }^{2}\right)$ was fixed at 0.80 based on modelling of 161 the first data point of the $\mathrm{Fe}_{2}\left(\mathrm{SO}_{4}\right)_{3}$ solution. The coordination number $(\mathrm{CN})$, average interatomic 162 distance $(\mathrm{R})$, and phase shift $\left(\Delta \mathrm{E}_{\mathrm{o}}\right)$ were used as adjustable fitting parameters during modelling of the 163 spectra. Initial tests allowing the Debye-Waller factor $\left(\sigma^{2}\right)$ to vary for the $\mathrm{Fe}-\mathrm{O}$ and $\mathrm{Fe}-\mathrm{Fe}$ 164 coordination shells were undertaken on a goethite sample measured at the same time under identical 165 beamline and experimental conditions (Boland et al., 2013). With the exception of the interatomic 166 distance of the edge sharing Fe-Fe atoms (at $3.013 \AA$ ) which were overestimated by $0.021 \AA$, these 167 tests showed that the $\mathrm{Fe}-\mathrm{O}$ and $\mathrm{Fe}-\mathrm{Fe}$ interatomic distances could be reproduced to crystallographic 168 data to within $0.007 \AA$ or better (Figure A2).

169 Upon modelling of the data, however it was observed that this approach confounded the detection of 170 the Fe shells when they first started appearing by producing large $\sigma^{2}$ values (which subsequently 171 decreased during extended polymerization). To overcome this problem the data were subsequently 172 modelled with $\sigma^{2}$ being fixed to 0.01 for the Fe-Fe shells. While this had little impact on the 173 modelled Fe-O and Fe-Fe interatomic distances (e.g. < $0.01 \AA$, Figure A2), this modelling approach 174 renders comparison of $\mathrm{Fe}$ shell $\mathrm{CN}$ results to previous literature difficult. Nevertheless, this still 175 allows direct comparison between the $\mathrm{Fe} \mathrm{CN}$ results for the data sets produced in this study.

176 The $\mathrm{F}$ test (Downward et al., 2007) at a probability of $p<0.05$ was used to test the statistical 177 significance of 1) adding a second $\mathrm{Fe}-\mathrm{O} / \mathrm{Cl}$ phase and amplitude function to model the first 178 coordination shell, 2) adding the Fe-Fe coordination shells to the fits, 3) allowing the $\mathrm{CN}$ of the first 179 coordination shell to vary, and 4) adding higher order cumulants $C_{3}$ and $C_{4}$ to modelling the first 180 coordination shell. 


\section{RESULTS}

\subsection{Thermodynamic equilibrium speciation calculations}

185 Speciation calculations were undertaken over the $\mathrm{pH}$ range of the XAS experiments (total Fe $\mathrm{F}^{\mathrm{III}}=0.33$

$186 \mathrm{M})$ to provide an initial basis for subsequent DFT structural optimizations of the major $\mathrm{Fe}^{\mathrm{III}}$ species 187 expected to be present during hydrolysis (Figure 1a). In all cases, $\mathrm{Fe}^{3+}$ (hexaquo water molecules 188 ignored in the notation) was calculated to be a major aqueous species before precipitation of 189 ferrihydrite or schwertmannite. Aqueous complexes with the respective counter-anions were also 190 predicted to be major contributors to the speciation of $\mathrm{Fe}^{\mathrm{III}}$ (Figure 1a). The dimer $\left(\mathrm{Fe}_{2}(\mathrm{OH})_{2}{ }^{4+}\right)$ and 191 trimer $\left(\mathrm{Fe}_{3}(\mathrm{OH})_{4}{ }^{5+}\right)$ were the only hydrolysis species calculated to be present at significant 192 concentrations, however, these two polymeric cations were not predicted to form in the $\mathrm{Fe}_{2}\left(\mathrm{SO}_{4}\right)_{3}$ 193 solution (Figure 1a). It is acknowledged, however, that, of the polymeric species, compelling 194 experimental evidence only exists for the dimer (Zhu et al., 2013). Neglecting the trimer from the 195 calculations resulted in greater concentrations of the dimer during hydrolysis (by up to a factor of $\sim 2$, 196 Figure 1b), but had very little influence on the concentrations of the monomeric species. In either case all other hydrolysis species (including the first, second and third monomeric hydrolysis species) contributed $<5 \%$ to the speciation of $\mathrm{Fe}^{\mathrm{III}}$ during hydrolysis.

\subsection{Density functional theory computations}

201 Density functional theory computations were undertaken to predict the most thermodynamically stable structures of the major aqueous Fe ${ }^{\mathrm{III}}$ species shown in Figure 1a. For most of the species, multiple structural entities were optimized to examine the likelihood of two (or more) thermodynamically stable structures coexisting. Using the ratio of the Boltzmann distribution, given as,

$$
\frac{\text { Structure } 1}{\text { Structure } 2}=e^{(E 2-E 1) / k T}
$$

208 the co-existence ratio of the first (Structure 1) and second (Structure 2) thermodynamically most 209 favorable structures can be calculated, where $E_{1}$ and $E_{2}$ are the Gibbs free energy values (eV) of the 210 two structural entities of the one species (or reaction products in Table 1), the Boltzmann constant $(k)$ $211=8.6173324 \times 10^{-5} \mathrm{eV} / \mathrm{K}$ and $T=298.15 \mathrm{~K}$ (the Gibbs free energy values in Table 1 are provided as $212 \mathrm{~kJ} / \mathrm{mol}$ but can be converted to $\mathrm{eV}$ by dividing by 96.4853). For example, an energy difference of 
$213 \sim 7.4 \mathrm{~kJ} / \mathrm{mol}$ between two structures (reaction products) results in a co-existence ratio of 20:1. The

214 smallest energy difference between the first and second thermodynamically most favorable structures

215 listed in Table 1 is $8.8 \mathrm{~kJ} / \mathrm{mol}$ for the trimer, resulting in a ratio of 35:1. It is, therefore, apparent that

216 the thermodynamically most favorable structures listed in Table 1 would be dominant.

217 The optimizations performed here resulted in an average $\mathrm{Fe}-\mathrm{OH}_{2}$ distance of $2.015 \pm 0.002 \AA$ for 218 hexa-coordinated $\mathrm{Fe}\left(\mathrm{H}_{2} \mathrm{O}\right)_{6}{ }^{3+}$ (Figure 2a, Table 2). The structures of the inner- and outer-sphere $219 \mathrm{Fe}\left(\mathrm{ClO}_{4}\right)^{2+}, \mathrm{Fe}\left(\mathrm{NO}_{3}\right)^{2+}, \mathrm{Fe}\left(\mathrm{SO}_{4}\right)^{+}$and $\mathrm{FeCl}_{2}{ }^{+}$complexes have been investigated rarely, if at all, with 220 DFT (Hill and Schauble, 2008; Zakharov et al., 2001). The inner-sphere complexes were calculated 221 to be thermodynamically more stable (Table 1) than outer-sphere 'ion pairs', as suggested by the 222 thermodynamic equilibrium speciation calculations (Figure 1a). The common effects of 223 complexation with $\mathrm{ClO}_{4}^{-}, \mathrm{NO}_{3}^{-}$and $\mathrm{SO}_{4}{ }^{2-}$ on the structure of the resultant complex included 224 distortion in octahedral geometry with shorter Fe-O distances to the anion(s) (Figures 2b-e). For 225 example, the $\mathrm{Fe}-\mathrm{O}$ distances between $\mathrm{Fe}-\mathrm{O}_{4} \mathrm{Cl}, \mathrm{Fe}-\mathrm{O}_{3} \mathrm{~N}$ and $\mathrm{Fe}-\mathrm{O}_{4} \mathrm{~S}$ were, respectively, $1.944 \AA$, $2261.940 \AA$ and $1.986 \pm 0.044 \AA$ (Table 2). The average $\mathrm{Fe}-\mathrm{O}$ distances for the $\mathrm{Fe}\left(\mathrm{H}_{2} \mathrm{O}\right)_{5}\left(\mathrm{ClO}_{4}\right)^{2+}$ and $227 \mathrm{Fe}\left(\mathrm{H}_{2} \mathrm{O}\right)_{5}\left(\mathrm{NO}_{3}\right)^{2+}$ complexes were extremely similar, $2.020 \pm 0.044 \AA$ and $2.023 \pm 0.050 \AA$, 228 respectively (Table 2), and therefore $<0.01 \AA$ longer than that for $\mathrm{Fe}\left(\mathrm{H}_{2} \mathrm{O}\right)_{6}{ }^{3+}$. These calculations 229 suggest that it would be difficult to distinguish these two complexes from $\mathrm{Fe}\left(\mathrm{H}_{2} \mathrm{O}\right)_{6}{ }^{3+}$ with XAS 230 based on average Fe-O distances. The average $\mathrm{Fe}-\mathrm{O}$ distance for $\mathrm{Fe}\left(\mathrm{H}_{2} \mathrm{O}\right)_{4}\left(\mathrm{SO}_{4}\right)^{+}$and the minor $231 \mathrm{Fe}\left(\mathrm{H}_{2} \mathrm{O}\right)_{2}\left(\mathrm{SO}_{4}\right)_{2}{ }^{-}$species were $\sim 0.03-0.05 \AA$ longer at $2.045 \pm 0.055 \AA$ and $2.063 \pm 0.059 \AA$, 232 respectively (Table 2), suggesting that the presence of these complexes with $\mathrm{Fe}\left(\mathrm{H}_{2} \mathrm{O}\right)_{6}{ }^{3+}$ would 233 manifest in slighter longer Fe-O distances being measured by XAS.

234 The 1:1 and 1:2 ferric chloride complexes were rather different (Figures 2f-g) having much longer 235 (average) $\mathrm{Fe}-\mathrm{Cl}$ distances of, respectively, 2.215 and $2.263 \pm 0.006 \AA$ and average $\mathrm{Fe}-\mathrm{O}$ bond 236 distances to the remaining water molecules of $2.066 \pm 0.030$ and $2.124 \pm 0.033 \AA$ (Table 2 ). In 237 these computations the $c$ is isomer of the 1:2 complex was predicted to be thermodynamically more 238 stable than the trans isomer.

239 Despite its classical hydroxy formula, the charge (4+) given to the dimeric species (Knight and 240 Sylva, 1975; Milburn and Vosburgh, 1955; Sommer and Margerum, 1970) suggests Fe-O-Fe 241 bonding could be either through two $\mathrm{OH}$ groups or one $\mathrm{O}$ atom. The latter (Figure 3a) was calculated 242 here as the thermodynamically most stable structure (Table 1). The two Fe-O distances through the 243 bridging $\mathrm{O}$ atom are almost identical at $1.831 \pm 0.001 \AA$ and the average Fe-O distance is $2.046 \pm$ $2440.114 \AA$. The distance between the two Fe atoms is $3.495 \AA$ with a resulting $\mathrm{Fe}-\mathrm{O}-\mathrm{Fe}$ bond angle of $245145^{\circ}$ (Figure 3a). A reduction in the coordination of either or both $\mathrm{Fe}$ atoms resulted in structures 
that were energetically less favorable indicating that hexa-coordination was thermodynamically preferred (Table 1).

248 A number of Fe-O-Fe bonding topologies can be consistent with the 5+ charge assigned to the 249 speculative trimeric hydrolysis species (Arnek and Schlyter, 1968; Bottero et al., 1994). Some 250 examples of the types of structures investigated are provided in Table 1. In contrast to the dimer, it 251 was observed that a trimer consisting solely of Fe-OH-Fe bonding was thermodynamically most 252 favorable (Table 1) with two hexa-coordinated $\mathrm{Fe}$ atoms edge sharing with the third hexa253 coordinated Fe atom linked via double corner bonding (Figure 3b). As observed for the dimer, 254 decreasing coordination to penta- or tetra-coordination was energetically unfavorable also suggesting 255 that hexa-coordination for all Fe atoms was thermodynamically most favorable (Table 1). The Fe-Fe 256 distance of $3.051 \AA$ obtained for this structure is comparable to edge sharing Fe octahedra in $\mathrm{Fe}^{\mathrm{III}}$ 257 (oxyhydr)oxides, but the Fe-Fe distance at $3.595 \pm 0.008 \AA$ is more indicative of single corner 258 sharing rather than double corner sharing in $\mathrm{Fe}^{\mathrm{III}}$ (oxyhydr)oxides (Manceau and Drits, 1993). 259 Nevertheless, these structural optimizations suggest that the simultaneous formation of the dimeric 260 and the trimeric hydrolysis species (Figure 1) would manifest in XAS by the appearance of Fe 261 neighbors at these distances and an increase in the average $\mathrm{Fe}-\mathrm{O}$ distance might also be detectable by 262 XAS (Table 2).

263 The interatomic distances listed in Table 2 for ferrihydrite and schwertmannite are those based on 264 pair distribution function (PDF) refinements of high-energy X-ray total scattering data (Fernandez265 Martinez et al., 2010; Michel et al., 2007a). The average Fe-O bond distance for (2-line) ferrihydrite 266 is approximately $0.017 \AA$ shorter than that calculated by DFT for $\mathrm{Fe}\left(\mathrm{H}_{2} \mathrm{O}\right)_{6}{ }^{3+}$ whereas for 267 schwertmannite it is almost identical at $2.020 \AA$ (Table 2). A decrease in average Fe-O bond 268 distances during ferrihydrite precipitation would be expected based on these results. Due to the 269 overlapping backscattering distances it would be difficult to differentiate transformations from the 270 dimer/trimer to ferrihydrite/schwertmannite based on Fe-Fe distances alone. However, the proposed 271 structure for ferrihydrite (Michel et al. 2007a) includes Fe tetrahedra and, while the Fe-Fe distances 272 are not directly indicative of tetrahedral geometry (Maillot et al., 2011), there are other features in 273 XAS spectra which are sensitive to this type of geometry change (Maillot et al., 2011; Mikutta, 2011; 274 Westre et al., 1997). In addition, it is also clear from the proposed ferrihydrite and schwertmannite 275 structures that the magnitude of Fe-Fe backscattering between these two minerals should be 276 noticeably different with relatively more intense backscattering occurring at $>3.4 \AA$ in ferrihydrite 277 (relative to that occurring from the edge sharing Fe atoms at 3.0 А, Table 2).

\subsection{Extended X-ray Absorption Fine Structure (EXAFS) Spectroscopy}




\subsubsection{General trends and single and multiple scattering at $\mathrm{OH}: \mathrm{Fe}=\mathrm{O}$}

282 Systematic changes are clearly evident in the Fourier-transformed EXAFS spectra during $\mathrm{Fe}^{\text {III }}$ 283 hydrolysis and precipitation in all the solutions (Figure 4; raw EXAFS data are presented in Figure 284 A3). Trends in spectral modifications are highlighted by the difference spectra also shown in Figure 2854 which represent the difference between the initial (red) spectrum $(\mathrm{OH}: \mathrm{Fe}=0)$ and the other 286 spectra. It is important to note that Fourier-transformed difference EXAFS spectra appear positive in 287 magnitude regardless of whether the difference in magnitude in the Fourier-transformed EXAFS 288 spectra (of the data) is negative or positive. The reduction in the amplitude of the first intense peak 289 in the Fourier-transformed data, which is representative of the first coordination shell with oxygen 290 (and $\mathrm{Cl}$ for the $\mathrm{FeCl}_{3}$ solution), can result from either a decrease in $\mathrm{CN}$ or an increase in variability of 291 the average bond length, i.e. bond distortion/disorder. Multiple scattering from the first coordination 292 shell is also evident in the spectra out to $4.0 \AA$ (phase uncorrected) during the early stages of 293 hydrolysis and is similar for the $\mathrm{Fe}\left(\mathrm{ClO}_{4}\right)_{3}$ and $\mathrm{Fe}\left(\mathrm{NO}_{3}\right)_{3}$ solutions which, in turn, are dissimilar to the $\mathrm{FeCl}_{3}$ and $\mathrm{Fe}_{2}\left(\mathrm{SO}_{4}\right)_{3}$ solutions. Indeed, scattering between the latter two solutions is also visibly dissimilar, particularly between 2 to $3 \AA$ (phase uncorrected) and is suggestive of additional (or different) $\mathrm{Fe}^{\mathrm{III}}$ species being present (Figure 4). In general, multiple scattering decreases in magnitude as hydrolysis progresses until single scattering from Fe backscatterers dominates in this distance range. A noticeable contribution from $\mathrm{Fe}$ backscatterers between 2 to $3 \AA$, phase uncorrected, in the solutions appears almost immediately upon hydrolysis (Figure 4) consistent with thermodynamic equilibrium speciation calculations (Figure 1) - with the exception of the $\mathrm{Fe}_{2}\left(\mathrm{SO}_{4}\right)_{3}$ solution.

In order to gain further structural insights from the EXAFS spectral trends, modelling of the spectra at $\mathrm{OH}: \mathrm{Fe}=0$ with both single and multiple scattering pathways of the first coordination shell was undertaken. The initial spectra of the $\mathrm{Fe}\left(\mathrm{ClO}_{4}\right)_{3}$ and $\mathrm{Fe}\left(\mathrm{NO}_{3}\right)_{3}$ solutions were easily modelled, based on octahedral geometry, using one single scattering Fe-O pathway at $\sim 2.01 \AA$, an orthogonal Fe-OO-Fe multiple scattering pathway at $\sim 3.54 \AA$ and three other (linear) multiple scattering pathways at $\sim 4.03 \AA$ (full fitting results are provided in Table A3 and the model fits in Figure A4). The three longer scattering pathways were fixed to the same interatomic distance as allowing these distances to vary led to results where the differences were $<0.06 \AA$ (which is below the resolution permitted with the $\mathrm{k}$ range used here for modelling). The orthogonal Fe-O-O-Fe multiple scattering pathway at $\sim 3.54 \AA$ is longer than that expected $(\sim 3.43 \AA)$ for a symmetrical octahedral $\mathrm{Fe}\left(\mathrm{H}_{2} \mathrm{O}\right)_{6}{ }^{3+}$ species with an average Fe-O interatomic distance of $\sim 2.01 \AA$ but, as its magnitude decreases simultaneously with distortion/disorder in the first coordination shell (Figure 4), it seems the most plausible scattering 
314 pathway. Nevertheless, its contribution to the EXAFS signal is weak as its inclusion in modelling 315 only significantly improved $(p<0.05)$ the fit of the initial spectrum of the $\mathrm{Fe}\left(\mathrm{NO}_{3}\right)_{3}$ solution and not 316 that of the $\mathrm{Fe}\left(\mathrm{ClO}_{4}\right)_{3}$ solution. The thermodynamic equilibrium speciation calculations in Figure 1 317 indicate that the dimeric species would be present at significant concentrations at an $\mathrm{OH}: \mathrm{Fe}$ ratio of 0 318 in the $\mathrm{Fe}\left(\mathrm{NO}_{3}\right)_{3}$ solution and, based on the DFT computations, a single scattering Fe-Fe pathway 319 around this interatomic distance could also explain this feature. Attempts to include a single 320 scattering Fe-Fe pathway between 3.5 - $3.6 \AA$, however, resulted in unrealistic CNs and Debye321 Waller factors.

322 Nevertheless, UV-vis spectra recorded for the $\mathrm{OH}: \mathrm{Fe}=0$ solutions (Figure A5) showed that weak 323 bands at 447 and $497 \mathrm{~nm}$, which have been suggested to arise from the presence of a $\mu$-oxo dimer 324 species (Zhu et al., 2016; Zhu et al., 2013), were evident in the $\mathrm{Fe}\left(\mathrm{NO}_{3}\right)_{3}$ solution. These bands were 325 absent from the other three solution spectra and, in agreement with thermodynamic speciation 326 calculations (Figure 1), could suggest that this species was only present at significant concentrations 327 in the $\mathrm{Fe}\left(\mathrm{NO}_{3}\right)_{3}$ solution, though below the threshold amenable to detection by non-linear least 328 squares fitting.

329 Modelling of the spectrum obtained for the $\mathrm{FeCl}_{3}$ solution at $\mathrm{OH}: \mathrm{Fe}=0$ with the same single and 330 multiple scattering pathways used for the $\mathrm{Fe}\left(\mathrm{ClO}_{4}\right)_{3}$ and $\mathrm{Fe}\left(\mathrm{NO}_{3}\right)_{3}$ solutions resulted in a poor fit, 331 however, this was significantly $(p<0.05)$ improved by inclusion of a single scattering $\mathrm{Fe}-\mathrm{Cl}$ 332 pathway at $\sim 2.28 \AA$ (Figure A6 with full fitting results in Table A3). The effect of this scattering 333 pathway is clearly evident in the Fourier-transformed data through destructive interference with the 334 Fe-O pathway around $\sim 2.2 \AA$, phase uncorrected (Figure 4). The remaining multiple scattering 335 distances were similar (and statistically significant at $p<0.05$ ) to those modelled for the $\mathrm{Fe}\left(\mathrm{ClO}_{4}\right)_{3}$ 336 and $\mathrm{Fe}\left(\mathrm{NO}_{3}\right)_{3}$ solutions, suggesting that orthogonal multiple scattering involving $\mathrm{Cl}$ is extremely 337 weak compared to that from O. Nevertheless, evidence for multiple scattering involving $\mathrm{Cl}$ would 338 appear to exist beyond that modelled to $4.00 \AA$, phase uncorrected (Figure A6). Indeed, multiple 339 scattering between $\mathrm{O}$ and $\mathrm{Cl}$ and/or $\mathrm{Cl}$ and $\mathrm{Cl}$ could be included in the modelling with reasonable 340 parameters, but their inclusion either resulted in little improvement to, or actually decreased, the 341 quality of the fit (data not shown). As a result, neither multiple scattering pathway was included in 342 the modelling shown in Figure A6.

343 The distance of $\sim 3.47 \AA$ obtained for the orthogonal Fe-O-O-Fe multiple scattering pathway of the 344 first spectrum in $\mathrm{Fe}_{2}\left(\mathrm{SO}_{4}\right)_{3}$ solution is $\sim 0.08 \AA$ shorter than that modelled for the other solutions. 345 The inclusion of this pathway was significant $(p<0.05)$. Although the average Fe-O bond distance 346 measured was slightly shorter than in the other solutions at $2.002 \AA$, the shorter (average) distance 347 obtained for the orthogonal multiple scattering could also arise through complexation with $\mathrm{SO}_{4}{ }^{2-}$, 
resulting in a shorter average $\mathrm{O}-\mathrm{O}$ interatomic distance. For example, based on the DFT 349 computations described in section 3.2, the distance between the bridging $\mathrm{O}$ groups of the major $350 \mathrm{Fe}\left(\mathrm{H}_{2} \mathrm{O}\right)_{4}\left(\mathrm{SO}_{4}\right)^{+}$complex is significantly shorter (i.e. $2.356 \AA$ compared to $\sim 2.85 \AA$ in $\left.\mathrm{Fe}\left(\mathrm{H}_{2} \mathrm{O}\right)_{6}{ }^{3+}\right)$. 351 A very weak single scattering pathway for Fe-S at $\sim 2.62 \AA$ could also be included in the modelling 352 (Figure A6), but it did not significantly $(p<0.05)$ improve the fit. Due to its very weak contribution 353 to the spectrum, it could therefore be purely coincidental that this $\mathrm{Fe}-\mathrm{S}$ interatomic distance is 354 remarkably similar to that calculated for the $\mathrm{Fe}\left(\mathrm{H}_{2} \mathrm{O}\right)_{4}\left(\mathrm{SO}_{4}\right)^{+}$complex $(2.635 \AA)$.

355 Based on these results, the shell fitting described below only considered $\mathrm{Cl}$ as an additional single scattering pathway in the first coordination shell of $\mathrm{Fe}$ in the $\mathrm{FeCl}_{3}$ solution. Furthermore, as there were generally monotonic increases or decreases around interatomic distances for both single and multiple scattering paths (Figure 4), no other additional scattering pathways were examined, except for Fe-Fe single scattering pathways arising from polymerization. Finally, as the contribution of multiple scattering to the EXAFS signal appeared to diminish with hydrolysis (Figure 4), these scattering pathways were omitted from further modelling, but are discussed in further detail when results for the Fe-Fe single scattering paths are presented in section 3.3.4.

\subsubsection{Shell by shell fitting - modelling of the first coordination shell with one shell}

Initially, modelling of the first coordination shell was restricted to one $\mathrm{Fe}-\mathrm{O}$ phase and amplitude function and the statistical significance of varying the $\mathrm{CN}$ against maintaining a fixed $\mathrm{CN}$ at 6 (i.e. octahedral geometry) was determined. Model fits for the Fe-O coordination shell in the $\mathrm{Fe}_{2}\left(\mathrm{SO}_{4}\right)_{3}$ solution were not statistically $(p<0.05)$ improved when the $\mathrm{CN}$ was allowed to vary from 6 but fits were improved for all the other solutions at CNs $<5.4$ (Tables A4-A7 with model fits, including FeFe pathways, shown in Figures A6-A9). Modelling results with one Fe-O phase and amplitude function, allowing $\mathrm{CN}, \mathrm{R}, \sigma^{2}$ and $\Delta \mathrm{E}_{\mathrm{o}}$ to vary, were then compared to results obtained with the 372 inclusion of the higher order cumulants $C_{3}$ (related to interatomic distance) and $C_{4}$ (related to $\mathrm{CN}$ 373 and, to a lesser extent, $\left.\sigma^{2}\right)$. Except in the case of one spectrum collected for the $\mathrm{Fe}\left(\mathrm{NO}_{3}\right)_{3}$ solution 374 (Table A5), including these cumulants did not significantly $(p<0.05)$ improve the fitting results (Bunker, 1983; Dalba and Fornasini, 1997) and the same trends in the fitting parameters CN, R, $\sigma^{2}$ were maintained regardless of the inclusion of $C_{3}$ and $C_{4}$ (data not shown). These results demonstrate that the Fe-O coordination shell could almost always be adequately modelled by a Gaussian approximation such that use of the EXAFS equation provides valid modelling results when using only one Fe-O phase and amplitude function when the k range of data is limited to $12 \AA^{-1}$. 
380 The fitting parameters $\mathrm{CN}, \mathrm{R}$ and $\sigma^{2}$ are plotted in Figure 5 as a function of $\mathrm{pH}_{\mathrm{F}}$ and $(\mathrm{OH}: \mathrm{Fe})$. In

381 Figure 5 it can be observed that the average Fe-O interatomic distance before the addition of any 382 base (i.e. $\mathrm{OH}: \mathrm{Fe}=0$ ), for all solutions was 2.00 to $2.01 \AA$. Based on the calculations in Figure 1 , the $383 \mathrm{Fe}\left(\mathrm{H}_{2} \mathrm{O}\right)_{5}(\mathrm{Cl})^{2+}$ and $\mathrm{Fe}\left(\mathrm{H}_{2} \mathrm{O}\right)_{4}(\mathrm{Cl})_{2}{ }^{+}$complexes would be expected to contribute to an increased $\mathrm{Fe}-\mathrm{O}$ 384 bond distance in the $\mathrm{FeCl}_{3}$ solution. This was observed, with the average $\mathrm{Fe}-\mathrm{O}$ bond distance being $385 \sim 0.01 \AA$ longer than that measured in the other solutions (at similar OH:Fe ratios), which is 386 qualitatively comparable to that expected from the DFT computations (Table 2) and thermodynamic 387 equilibrium calculations (Figure 1).

388 As hydrolysis progressed, the average Fe-O bond distance increased by a maximum of $\sim 0.03 \AA$ at an 389 OH:Fe ratio of $\sim 1$, except in the $\mathrm{Fe}_{2}\left(\mathrm{SO}_{4}\right)_{3}$ solution. Although the inclusion of Fe backscatterers in 390 model fits did not become statistically significant until around this OH:Fe ratio, or later (discussed 391 further below), it is clear from the difference spectra shown in Figure 4 that there is an immediate 392 increase in magnitude around $\sim 3.04 \AA$ which is indicative of Fe backscatterers in edge-edge coordination. The results, therefore, indicate that the mean Fe-O bond distances until this point are already representative of both monomeric and polymeric species. Based on the DFT results, the increase in Fe-O interatomic distances would be consistent with the formation of the dimer or trimer (Table 2). The trend in Fe-O bond distances for the $\mathrm{Fe}_{2}\left(\mathrm{SO}_{4}\right)_{3}$ solution is clearly different to the other solutions over this $\mathrm{OH}: \mathrm{Fe}$ range, indicating the formation of different hydrolysis species. While deprotonation of $\mathrm{HSO}_{4}{ }^{-}$might obfuscate the $\mathrm{OH}: \mathrm{Fe}$ ratios measured during the titration of this solution, this is unlikely given that the final $\mathrm{OH}: \mathrm{Fe}$ ratios plateaued at $\sim 3$ and that the final five XAS spectra were essentially identical - indicating complete $\mathrm{Fe}^{\mathrm{III}}$ transformations (Table A7). This, in turn, provides evidence that $\mathrm{SO}_{4}{ }^{2-}$ does not suppress $\mathrm{Fe}^{\mathrm{III}}$ hydrolysis over this $\mathrm{OH}: \mathrm{Fe}$ range. As the average $\mathrm{Fe}-\mathrm{O}$ bond distances decrease from their maxima, the contribution of $\mathrm{Fe}$ backscatterers to the spectra continue to increase (Figure 4). As noted in section 3.2, a decrease in the $\mathrm{Fe}-\mathrm{O}$ bond distance prior to, and concurrent with, polymerization would be consistent with the formation of ferrihydrite. At (or near) complete hydrolysis the average $\mathrm{Fe}-\mathrm{O}$ bond distances in the polymers/precipitates cluster around $\sim 1.985 \AA$ for the $\mathrm{Fe}\left(\mathrm{ClO}_{4}\right)_{3}$ and $\mathrm{Fe}\left(\mathrm{NO}_{3}\right)_{3}$ solutions and $\sim 1.990$ $\AA$ for the $\mathrm{Fe}(\mathrm{Cl})_{3}$ and $\mathrm{Fe}_{2}\left(\mathrm{SO}_{4}\right)_{3}$ solutions.

Trends in the $\mathrm{CN}$ and Debye-Waller factor for the Fe-O coordination shell are also shown in Figure 5. The $\mathrm{CN}$ results are once again clearly different for the $\mathrm{Fe}_{2}\left(\mathrm{SO}_{4}\right)_{3}$ solution compared to the other iron salt solutions. While there is a relatively large degree of uncertainty associated with the determination of CNs, particularly in regards to the effects from disorder, the Debye-Waller factors are essentially identical for all solutions when plotted as a function of the molar hydrolysis ratio 
413 (Figure 5). When plotted against $\mathrm{pH}_{\mathrm{F}}$, the Debye-Waller factors for the $\mathrm{Fe}_{2}\left(\mathrm{SO}_{4}\right)_{3}$ solution are 414 actually higher than for the other iron salt solutions. This observation suggests that the decreasing 415 trend in $\mathrm{CN}$ for the $\mathrm{Fe}-\mathrm{O}$ coordination shells of the other three solutions results from disorder rather 416 than being classically expressed in the Debye-Waller factor. This is further supported by the 417 statistical analyses described above which showed that allowing the $\mathrm{CN}$ to vary for the $\mathrm{Fe}-\mathrm{O}$ 418 coordination shell significantly improved $(p<0.05)$ fits when the $\mathrm{CN}$ was $<5.4$ (Tables A4-A7). 419 Overall, these results suggest that the formation of a common $\mathrm{Fe}^{\mathrm{III}}$ specie in the $\mathrm{Fe}\left(\mathrm{ClO}_{4}\right)_{3}, \mathrm{Fe}\left(\mathrm{NO}_{3}\right)_{3}$ 420 and $\mathrm{FeCl}_{3}$ solutions is inhibited by sulfate, in agreement with thermodynamic equilibrium 421 calculations (Figure 1).

\subsubsection{Shell by shell fitting - modelling of the first coordination shell with two shells}

424 A fitting approach invoking $\mathrm{Fe}-\mathrm{O}$ and $\mathrm{Fe}-\mathrm{Cl}$ scattering pathways significantly $(p<0.05)$ improved 425 the fitting of the first six data points of the $\mathrm{FeCl}_{3}$ solution (Table A6), but the destructive interference 426 between the $\mathrm{Fe}-\mathrm{O}$ and $\mathrm{Fe}-\mathrm{Cl}$ pathways was observable to an $\mathrm{OH}: \mathrm{Fe}$ ratio of 0.74 . Despite differences 427 in the experimental conditions of previous studies, the average interatomic distances obtained here 428 for $\mathrm{Fe}-\mathrm{O}$ and $\mathrm{Fe}-\mathrm{Cl}, \sim 2.02$ and $2.27 \AA$ respectively, are remarkably similar to those previously 429 reported (Bottero et al., 1994; Combes et al., 1989; Rose et al., 1996). There is also good agreement 430 between these bond distances and those calculated by DFT, particularly for the $\mathrm{Fe}\left(\mathrm{H}_{2} \mathrm{O}\right)_{4}(\mathrm{Cl})_{2}{ }^{+}$ 431 complex, but less so for $\mathrm{Fe}\left(\mathrm{H}_{2} \mathrm{O}\right)_{5}(\mathrm{Cl})^{2+}$ (Table 2), indicating that the stability constant for the $432 \mathrm{Fe}\left(\mathrm{H}_{2} \mathrm{O}\right)_{4}(\mathrm{Cl})_{2}{ }^{+}$complex could be higher than that used for the thermodynamic equilibrium 433 speciation calculations shown in Figure 1.

434 A two shell approach to modelling the first coordination shell of $\mathrm{Fe}$ in $\mathrm{Fe}^{\mathrm{III}}$ polymers/oxyhydroxides 435 has recently gained attention (Maillot et al., 2011; Manceau, 2011; Zhu et al., 2016) whereby 436 coordination pathways can be extracted from a coordination shell if the data permit a minimal spatial 437 resolution (i.e. $\Delta \mathrm{R}=\pi /(2 \Delta \mathrm{k}))$. To minimize correlations between the fitting parameters of the two 438 Fe-O paths, investigators have either 1) fixed the Debye-Waller factors to be equal (Maillot et al., 439 2013); or 2) subjectively fixed CNs (Manceau, 2011; Toner et al., 2009; Zhu et al., 2016; Zhu et al., 440 2013). As it is difficult to compare previous studies due to significant differences between data 441 quality and modelled $\mathrm{k}$ space regions, the three modelling approaches described above were used to 442 examine their effect on detecting the expected shorter Fe-O interatomic distance in the dimeric 443 species and/or ferrihydrite/schwertmannite from the first coordination shell in the $\mathrm{Fe}\left(\mathrm{ClO}_{4}\right)_{3}$ solution 444 data (i.e. the cleanest data set). The $\mathrm{Fe}_{2}\left(\mathrm{SO}_{4}\right)_{3}$ solution was also modelled in the same manner to 445 investigate further the differences in the results obtained based on the single shell Fe-O modelling 
446 described in section 3.3.2. To obtain sufficient spatial resolution, the $\mathrm{k}$ range used for Fourier 447 transformation was extended to $15.5 \AA^{-1}$, providing a resolution of $0.101 \AA$. Testing the modelling 448 approaches on goethite revealed that fixing the Debye-Waller factors to be equal resulted in the most 449 accurate determination of Fe-O interatomic distances, followed by fixing the CNs to be equal and 450 finally allowing all of the fitting parameters to vary (Figure A2). To improve the spectral signal-to451 noise ratio of the final precipitated phases, the final six spectra of the $\mathrm{Fe}\left(\mathrm{ClO}_{4}\right)_{3}$ and final four spectra 452 of the $\mathrm{Fe}_{2}\left(\mathrm{SO}_{4}\right)_{3}$ solution were merged.

453 It can be seen in Figure A10 (fits shown in Figure A11) that the interatomic distances of the longer 454 average $\mathrm{Fe}-\mathrm{O}$ bond $(\sim 2.05 \AA)$ for the $\mathrm{Fe}\left(\mathrm{ClO}_{4}\right)_{3}$ solution were almost identical when either the $\mathrm{CN}$ or 455 the Debye-Waller factor were fixed to be equal. While there was initially good agreement between 456 the interatomic distances of the shorter average Fe-O bond $(\sim 1.95 \AA)$, the results significantly 457 diverged between $\mathrm{pH}_{\mathrm{F}}$ of $2.00-2.23$ with $\mathrm{Fe}-\mathrm{O}$ bond distances at $1.80-1.85 \AA$ being fitted when the 458 Debye-Waller factors were equal (Figure A10). These bond distances were also reproduced when all 459 fitting parameters were allowed to vary at $\mathrm{pH}_{\mathrm{F}} 2.00$ and 2.11 which corresponds to the point at which 460 the maximum concentrations of the dimer would be expected to be present (Figure 1). The fitting 461 parameters of the final precipitated phase when either the Debye-Waller factor or CN were fixed to 462 be equal were almost identical (Figure A10), while the third approach resulted in estimated average 463 Fe-O interatomic distances of 1.885 and $2.002 \AA$.

464 When the Debye-Waller factor and $\mathrm{CN}$ were fixed to be equal for the $\mathrm{Fe}_{2}\left(\mathrm{SO}_{4}\right)_{3}$ solution, almost 465 identical Fe-O interatomic distances were obtained for all sample points (Figure A12, fits shown in 466 Figure A13) clustering around 1.94 and $2.04 \AA$. While the interatomic distances were significantly 467 different at 1.98 and $2.07 \AA$ (and thus below the minimal spatial resolution) when all fitting 468 parameters were allowed to vary, the trends were similar; i.e. there was no change in Fe-O 469 interatomic distances, except for the final solid phase where average interatomic distances shortened 470 to 1.902 and $2.022 \AA$.

471 Based on fitting the Fe-O coordination shell of goethite with the three modelling approaches, fixing 472 the Debye-Waller factors to be equal provided the most accurate results for $\mathrm{Fe}-\mathrm{O}$ interatomic 473 distances (Figure A2). Here, fixing the Debye-Waller factors or CNs to be equal gave Fe-O 474 interatomic distances having $<0.01 \AA$ difference for either of the solid phases precipitated from the 475 two solutions (Figures A10 and A12). However, the fits were generally improved when allowing all 476 of the parameters to vary. The respective shorter Fe-O interatomic distances obtained with this 477 approach (1.885 and $1.902 \AA$ ) would suggest that a certain proportion of $\mathrm{Fe}^{\mathrm{III}}$ tetrahedra may exist in 478 both solid phases, though it is acknowledged that the data quality here is inferior to that reported by 479 Maillot et al. (2011, 2013). 
480 While these results highlight some of the uncertainties in data interpretation introduced by modelling 481 the Fe-O shell with two scattering pathways, two of the three approaches involved fitting a short Fe$482 \mathrm{O}$ bond distance at $1.80-1.85 \AA$ in the $\mathrm{Fe}\left(\mathrm{ClO}_{4}\right)_{3}$ solution when the corresponding one shell Fe-O 483 average interatomic distances were at a maximum. These fitting results occur at the point when the 484 concentration of the $\mu$-oxo dimer would be expected to be at its maximum (Figure 1) and these short 485 Fe-O interatomic distances are similar to those in the dimer's DFT-optimized structure (Table 2).

\subsubsection{Full shell by shell fitting - modelling of the Fe-Fe coordination shells}

488 EXAFS studies examining the structure of Fe polymers and the processes of polymerization 489 following $\mathrm{Fe}^{\mathrm{III}}$ hydrolysis have largely focused upon changes occurring in the $\mathrm{Fe}-\mathrm{Fe}$ coordination 490 shells (Bottero et al., 1994; Combes et al., 1989; Mikutta, 2011; Pokrovski et al., 2003; Rose et al., 491 1996; Rose et al., 1997). In general agreement with the studies of Bottero et al. (1994) and Combes 492 et al. (1989), a monotonic increase in $\mathrm{CN}$ for Fe-Fe interatomic distances at $\sim 3.04$ and $\sim 3.43 \AA$ 493 ( 3.39 $\AA$ for the $\mathrm{Fe}_{2}\left(\mathrm{SO}_{4}\right)_{3}$ solution) was observed as hydrolysis progressed (Figure 6). The 494 significance of orthogonal and linear multiple scattering from an octahedral Fe-O coordination shell 495 in the Fe-Fe scattering region (when Fe-Fe scattering pathways became significant) was examined 496 and, although both significantly $(p<0.05)$ improved fitting results, the effective radius for the 497 orthogonal multiple scattering was centered at $\sim 3.37 \AA$ for all solutions (data not shown). This 498 distance is too close to the longer Fe-Fe interatomic distances measured for this multiple scattering 499 pathway to be resolved. In accord with a decrease in the average Fe-O bond distance, the linear 500 multiple scattering pathways shortened in length to $\sim 3.94 \AA$ (data not shown). Ultimately, multiple 501 scattering was not considered in the final fitting.

502 The shorter Fe-Fe scattering path significantly improved fitting before the longer Fe-Fe scattering 503 pathway (Tables A4-A7), as observed previously (Bottero et al., 1994; Combes et al., 1989). 504 However, the Fe-Fe contribution at $\sim 3.04 \AA$ is evident in the difference spectra before it became 505 statistically significant to the fitting of the data (Figure 4). The range in $\mathrm{OH}: \mathrm{Fe}$ values between 506 which the two paths became statistically significant to the fit varied greatly between the solutions, 507 ranging from $0.4-0.5$ for the $\mathrm{Fe}\left(\mathrm{ClO}_{4}\right)_{3}, \mathrm{Fe}\left(\mathrm{NO}_{3}\right)_{3}$ and $\mathrm{FeCl}_{3}$ solutions to 2 for the $\mathrm{Fe}_{2}\left(\mathrm{SO}_{4}\right)_{3}$ 508 solution (Tables A4-A7). The Fe-Fe contribution at $\sim 3.43 \AA$ only became statistically significant at $509 \mathrm{OH}: \mathrm{Fe} \geq 2$, but occurred much later for the $\mathrm{Fe}_{2}\left(\mathrm{SO}_{4}\right)_{3}$ solution $(\mathrm{OH}: \mathrm{Fe}=2.8)$.

510 The X-ray diffractograms of the final precipitates from the $\mathrm{Fe}\left(\mathrm{ClO}_{4}\right)_{3}$ and $\mathrm{Fe}\left(\mathrm{NO}_{3}\right)_{3}$ solutions 511 indicated that the $\mathrm{Fe}^{\mathrm{III}}$ minerals were extremely X-ray amorphous and showed two broad peaks 512 characteristic of 2-line ferrihydrite (Figure A15a). The solid phases precipitated from the $\mathrm{FeCl}_{3}$ and 
$513 \mathrm{Fe}_{2}\left(\mathrm{SO}_{4}\right)_{3}$ solutions were also particularly X-ray amorphous, but were somewhat dissimilar from that

514 formed from the other two solutions and both displayed a stronger peak centered at $\sim 352 \theta$ (Figure 515 A15a). Further FTIR-ATR analysis of the solid phase produced from the $\mathrm{Fe}_{2}\left(\mathrm{SO}_{4}\right)_{3}$ solution showed 516 distinctive features (Figure A15b) which have been observed for schwertmannite precipitated at 517 acidic pH values (Boily et al., 2010; Wang et al., 2015), indicating that schwertmannite precipitated 518 from this solution. No peaks attributable to either goethite or lepidocrocite were detected in the 519 spectra of all of the precipitated phases (Figure A15c).

\section{3.4 X-ray Absorption Near-Edge Spectroscopy (XANES)}

522 With the exception of the pre-edge region, changes in the XANES spectra of all the solutions were 523 monotonic during $\mathrm{Fe}^{\mathrm{III}}$ hydrolysis and precipitation (Figure 7a). Various regions of Fe K-edge 524 XANES spectra, marked as A to E in Figure 7a, have been attributed to aspects of Fe ${ }^{\mathrm{III}}$ geometry and 525 coordination with the pre-edge features (enlarged in Figure $7 b$ ) perhaps receiving the most attention 526 (Apted et al., 1985; Combes et al., 1989; Manceau and Gates, 1997; Mikutta, 2011; Westre et al., 527 1997).

\subsection{1 (Multiple) Scattering Resonances}

530 The (multiple scattering) resonance centered at $\sim 7148 \mathrm{eV}$, which montonically increases at A has 531 either been attributed to increasing distortion in $\mathrm{Fe}^{\mathrm{III}}$ octahedra (Pokrovski et al., 2003) or linked to 532 an increase in Fe ${ }^{\mathrm{III}}$ polymerization (Voegelin et al., 2010). The EXAFS results presented in sections $533 \quad$ 3.3.2 and 3.3.4 are, therefore, consistent with either of these interpretations. However, as Voegelin 534 et al. (2010) observed this resonance in a range of $\mathrm{Fe}^{\mathrm{III}}$ (oxyhydr)oxides (lepidocrocite, goethite, 535 hematite and maghemite), it is difficult to assign this resonance to aspects of geometry, interatomic 536 distance or bond angle, although all these minerals do contain edge-sharing Fe $\mathrm{F}^{\mathrm{III}}$ octahedra.

537 The (multiple scattering) resonance at $\sim 7138 \mathrm{eV}$, marked as B in Figure 7 a, has been related to Fe ${ }^{\mathrm{III}}$ 538 geometry, with an increase in absorption postulated to correspond to an increase in the proportion of 539 tetrahedral Fe ${ }^{\mathrm{III}}$ present (Katz et al., 2012; Pokrovski et al., 2003). Since this resonance decreased 540 with $\mathrm{Fe}^{\mathrm{III}}$ polymerization (also observed by Voegelin et al. (2010)), then the results presented here 541 would indicate that the content of tetrahedral $\mathrm{Fe}^{\mathrm{III}}$ decreases with hydrolysis and precipitation, if this 542 interpretation were correct.

\subsubsection{Edge region}


545 For a number of $1^{\text {st }}$ row divalent transition metals it has been shown that the peak of the white line, 546 corresponding to the $1 \mathrm{~s} \rightarrow 4 \mathrm{p}$ transition and marked as $\mathrm{C}$ in Figure $7 \mathrm{a}$, decreases in intensity as 547 distortion increases within the first coordination shell (Chaboy et al., 2006; Collins et al., 2010; 548 Fernando et al., 2010). Such an interpretation would be valid for the results obtained here based on 549 the EXAFS modelling reported in section 3.3.2. It has also been theoretically demonstrated that the 550 maximum intensity of the peak of the white line and its energy position can vary as a function of 551 average bond distance within the first coordination shell (Katz et al., 2012), with an average increase 552 in bond distance resulting in a more intense peak at lower energy and vice versa. In all of the 553 solutions studied here, there is only a slight monotonic decrease in the energy position of the peak of 554 the white line. As such, this suggests that there is either very little change in the average Fe-O bond 555 distance or that simultaneous bond elongation and shortening (i.e. distortion) results in no net effect. 556 Alternatively, it has also been reported that the intensity of the peak of the white line decreases as the 557 covalency of first coordination shell bonding increases (Sarangi, 2013). As the process of oxolation 558 would also be expected to result in greater Fe-O bond covalency, it is therefore also possible that this 559 feature may reflect changes in Fe-O bonding during hydrolysis.

560 In Figure 7a it can also be observed that the edge energy monotonically decreases as a function of 561 hydrolysis and precipitation, particularly in the lower 'half' of the edge (marked as D in Figure 7a) 562 where a maximum downward shift of $\sim 2 \mathrm{eV}$ was measured in the $\mathrm{Fe}\left(\mathrm{ClO}_{4}\right)_{3}$ and $\mathrm{Fe}\left(\mathrm{NO}_{3}\right)_{3}$ solutions. 563 Photoreduction of $\mathrm{Fe}^{\mathrm{III}}$ during the experiments is unlikely given that the solutions/suspensions were 564 only illuminated for 44 - $88 \mathrm{~s}$ approximately $18-20$ times over a $2 \frac{1}{2} \mathrm{hr}$ period. Indeed, the pre-edge 565 features provided confirmation that $\mathrm{Fe}$ existed solely in the $\mathrm{Fe}^{\mathrm{III}}$ oxidation state (section 3.4.3). The 566 edge energy can also decrease with increasing (average) interatomic distances within the first 567 coordination shell but, as shown in section 3.3.2., this is inconsistent with the corresponding trends in 568 EXAFS data. As with the peak of the white line, it has also been suggested that an increase in bond 569 covalency within the first coordination shell can decrease the edge energy (DeWitt, 1992; Sarangi, 570 2013). For example, DeWitt (1992) observed a positive relationship between this feature and the 571 covalency of first coordination shell bonding in $\mu$-oxo-bridged $\mathrm{Fe}^{\mathrm{III}}$ molecules and noted that its 572 appearance also reflected greater distortion in this coordination shell. As noted in section 3.3.2., 573 disorder increased in the first coordination shell as hydrolysis and precipitation progressed. 574 Furthermore, the process of oxolation, as mentioned above, would also be expected to result in 575 greater bond covalency. Therefore, the interpretation of DeWitt (1992) for this feature is consistent 576 with the results obtained here. 


\subsubsection{Pre-edge region}

579 The pre-edge feature marked as $\mathrm{E}$ in Figure $7 \mathrm{a}$ is attributed to a forbidden $1 \mathrm{~s} \rightarrow 3 \mathrm{~d}$ transition that can

580 be influenced by $4 \mathrm{p}$ mixing into the $3 \mathrm{~d}$ state and so provide $1 \mathrm{~s} \rightarrow 4 \mathrm{p}$ character to the transition 581 (Shulman et al., 1976; Westre et al., 1997). It has been well established that the intensity of the pre582 edge feature for high spin $\mathrm{Fe}^{\mathrm{III}}$ increases as a result of symmetry distortion at the metal site while maintaining the same geometry, or as the local coordination environment changes from octahedral to tetrahedral geometry where there is also greater $4 \mathrm{p}$ mixing due to a reduction in symmetry (Westre et al., 1997). Expansion of the pre-edge features (Figure 7b) indicates that all solutions show similar trends during $\mathrm{Fe}^{\mathrm{III}}$ hydrolysis and precipitation. For example, the pre-edge features of all the solutions at $\mathrm{OH}: \mathrm{Fe}=0$ show two peaks split by $\sim 1.4 \mathrm{eV}$, which has been observed for high-spin monomeric or dimeric $\mathrm{Fe}^{\mathrm{III}}$ in octahedral geometry coordinated to oxygen atoms (Westre et al., 1997). As hydrolysis proceeds, the intensity of the higher energy peak increases more than that of the lower energy peak, but this is possibly obfuscated by the absorption of the rising edge also increasing in approximately equal intensity. As polymerization becomes statistically significant (in the EXAFS region, section 3.3.2), the split peaks are no longer apparent and the peak of maximum intensity shifts downwards in energy by $\sim 0.4 \mathrm{eV}$ for the $\mathrm{FeCl}_{3}$ and $\mathrm{Fe}_{2}\left(\mathrm{SO}_{4}\right)_{3}$ solutions and by $\sim 1 \mathrm{eV}$ for the $\mathrm{Fe}\left(\mathrm{ClO}_{4}\right)_{3}$ and $\mathrm{Fe}\left(\mathrm{NO}_{3}\right)_{3}$ solutions.

595 To remove the confounding effects of the rising edge to the apparent absorption intensity of the preedge features, the data were 'background subtracted' by fitting an arc-tangent to the white line (Figure 8). It is clear from comparison of Figures $7 \mathrm{~b}$ and 8 that removal of the rising edge absorption greatly reduces the intensity of the high energy peak (when observable). A number of other trends in the pre-edge features that are not obvious in the normalized-only data also become readily apparent in Figure 8. This is most clearly demonstrated for the $\mathrm{Fe}\left(\mathrm{NO}_{3}\right)_{3}$ solution data. For example, while the trend in increasing intensity of the higher energy peak during the early stages of hydrolysis to an $\mathrm{OH}: \mathrm{Fe}$ ratio of $1.60\left(\mathrm{pH}_{\mathrm{F}}=2.14\right)$ is readily apparent (marked as trend $1 \mathrm{~b}$ on Figure 8), a concomitant increase (maximum of $\sim 0.5 \mathrm{eV}$ ) in the width of this peak also becomes obvious on its high energy side (marked as trend 1a). This would be expected given that peak width should increase with peak intensity.

After the maximum intensity of the higher energy peak was reached, two changes in the pre-edge features occurred simultaneously with the next increment in base addition $\left(\mathrm{OH}: \mathrm{Fe}=1.97, \mathrm{pH}_{\mathrm{F}}=\right.$ 2.23). The apparent width of the higher energy peak reduced dramatically to be similar to, or less than, the spectrum at an $\mathrm{OH}: \mathrm{Fe}$ ratio of 0 (trend $2 \mathrm{a}$ in Figure 8). At the same time, there was a downward shift in energy of the maximum peak intensity $(\sim 1 \mathrm{eV})$ but also a decrease in maximum 
611 absorption intensity (trend $2 \mathrm{~b}$ ). The latter trend is not clearly evident in the normalized-only data.

612 These changes occurred at the same time as single scattering from double corner-sharing $\mathrm{Fe}$

613 backscatterers significantly improved modelling of the EXAFS data (Table A5). Finally, there was a

614 gradual increase in absorption with no further shifts in energy of the peak maxima and only minimal

615 changes to peak width (trend 3). These trends are also apparent for the $\mathrm{Fe}\left(\mathrm{ClO}_{4}\right)_{3}$ solution and occur

616 at similar $\mathrm{OH}: \mathrm{Fe}$ ratios (where the significant presence of edge- and double corner-sharing $\mathrm{Fe}$

617 backscatterers occurs. The quality of the $\mathrm{FeCl}_{3}$ solution data is insufficient to derive definitive

618 conclusions. While the data for the $\mathrm{Fe}_{2}\left(\mathrm{SO}_{4}\right)_{3}$ solution showed similar trends, there are some marked

619 differences from the other solutions. For example, while there is an increase in peak intensity of the

620 higher energy peak during the early stages of hydrolysis (trend 1 in Figure 8), the maximum increase

621 in intensity is less than half that observed for the $\mathrm{Fe}\left(\mathrm{ClO}_{4}\right)_{3}$ and $\mathrm{Fe}\left(\mathrm{NO}_{3}\right)_{3}$ solutions and there are also

622 minimal changes to apparent peak widths. There is also a downwards shift in energy of the

623 maximum peak intensity (trend 2a), which occurs well after edge-sharing Fe backscatterers

624 significantly contributed to the EXAFS modelling $(\mathrm{OH}: \mathrm{Fe}=1.88$, Table A7), and increased

625 absorption (trend $2 \mathrm{~b}$ ), but both are also smaller than that observed in the other solutions.

\section{DISCUSSION}

\subsection{The structure of aqueous $\mathrm{Fe}^{\mathrm{III}}$ hydrolysis species and complexes}

630 In this study, DFT structural optimizations were performed with the COSMO dielectric continuum 631 solvation model to self-consistently include the influence of aqueous solvation (second hydration 632 shell and beyond) on the structure and energy of the aqueous species. With one exception 633 (Yamaguchi and Ohira, 2015), all previous studies have optimized structures in vacuo and then used 634 these fixed coordinates to obtain solvation and vibrational energies in aqueous phase models (de 635 Abreu et al., 2006; Kubicki, 2001; Martin et al., 1998; Ottonello and Zuccolini, 2009; Panina et al., 636 2010; Yang et al., 2013; Zhu et al., 2016; Zhu et al., 2013). The average Fe-OH $\mathrm{OH}_{2}$ distance of $2.015 \pm$ $6370.002 \AA$ obtained here for $\mathrm{Fe}\left(\mathrm{H}_{2} \mathrm{O}\right)_{6}{ }^{3+}$ (Figure 2a, Table 2) is $\sim 0.05 \AA$ shorter than that generally 638 reported for $\mathrm{Fe}\left(\mathrm{H}_{2} \mathrm{O}\right)_{6}{ }^{3+}$ in vacuo (de Abreu et al., 2006; Kubicki, 2001; Li et al., 1996; Martin et al., 639 1998) and agrees extremely well with that determined experimentally for the $\mathrm{OH}: \mathrm{Fe}=0$ solutions 640 (Figure 5). The average $\mathrm{Fe}-\mathrm{OH}_{2}$ distances for the inner-sphere $\mathrm{Fe}\left(\mathrm{H}_{2} \mathrm{O}\right)_{5}\left(\mathrm{ClO}_{4}\right)^{2+}$ and $641 \mathrm{Fe}\left(\mathrm{H}_{2} \mathrm{O}\right)_{5}\left(\mathrm{NO}_{3}\right)^{2+}$ complexes were extremely similar to that obtained for $\mathrm{Fe}\left(\mathrm{H}_{2} \mathrm{O}\right)_{6}{ }^{3+}$ and while the 642 EXAFS modelling (Figure 5) does not provide definitive proof of their presence, the experimental 643 results are in excellent agreement with the DFT optimized structures. 
644 It was clear from modelling the first coordination shell of the $\mathrm{FeCl}_{3}$ solution that there was inner645 sphere bonding between $\mathrm{Fe}$ and $\mathrm{Cl}$, in agreement with earlier work (Apted et al., 1985; Bottero et al., 646 1994; Combes et al., 1989; Pokrovski et al., 2003; Rose et al., 1996). In contrast to studies where it 647 has been assumed that the $\mathrm{Cl}$ anions are in the trans position based on the crystallographic structure 648 of $\mathrm{FeCl}_{3} 6 \mathrm{H}_{2} \mathrm{O}$ (Combes et al., 1989; Hill and Schauble, 2008), the DFT computations indicated that 649 the cis isomer of the 1:2 complex was thermodynamically more stable than the trans isomer. 650 Although the average $\mathrm{Fe}-\mathrm{Cl}$ bond distance of the trans isomer was approximately $0.04 \AA$ longer (data 651 not shown) than the cis form, the presence of a mixture of $\mathrm{Fe}\left(\mathrm{H}_{2} \mathrm{O}\right)_{3} \mathrm{Cl}^{2+}$ and $\mathrm{Fe}\left(\mathrm{H}_{2} \mathrm{O}\right)_{3} \mathrm{Cl}_{2}{ }^{+}$ 652 complexes makes it difficult to unequivocally confirm the theoretical result.

653 The only relatively large discrepancy between modelled bond distances and the DFT optimized 654 structures of the inner-sphere complexes was that obtained for the $\mathrm{Fe}\left(\mathrm{H}_{2} \mathrm{O}\right)_{4}\left(\mathrm{SO}_{4}\right)^{+}$complex. (Figure 6555 and Table 2). Although the thermodynamic equilibrium calculations in Figure 1 indicated that 656 complexation of $\mathrm{Fe}^{\mathrm{III}}$ by $\mathrm{SO}_{4}{ }^{2-}$ should substantially affect $\mathrm{Fe}$ speciation, a slightly longer average $\mathrm{Fe}$ $657 \mathrm{O}$ bond distance in this solution at $\mathrm{OH}: \mathrm{Fe}=0$, as predicted by the DFT computations, was not 658 observed. This difference raises the possibility that the complex optimized, $\mathrm{Fe}\left(\mathrm{H}_{2} \mathrm{O}\right)_{4}\left(\mathrm{SO}_{4}\right)^{+}$, is not 659 representative of the main species present. Although the number of bonding possibilities is restricted 660 by the charge assigned to this complex, the $\mathrm{pKa}$ of sulfate ( $\mathrm{pH}$ 1.97) somewhat complicates matters 661 as this anion will be present in varying proportions as $\mathrm{SO}_{4}{ }^{2-}$ and $\mathrm{HSO}_{4}{ }^{-}$over the $\mathrm{pH}$ range examined. 662 Nevertheless, the average Fe-O bond distance of a DFT optimized $\mathrm{Fe}\left(\mathrm{H}_{2} \mathrm{O}\right)_{3} \mathrm{OH}-\mathrm{HSO}_{4}$ complex was $6632.071 \AA$ (data not shown) - even longer than the thermodynamically most stable complex (Table 2). 664 Future use of alternative basis sets for S may eventually improve agreement with the experimental 665 data obtained here as inhibition of the formation of the dimer in this solution supports the presence of 666 strong inner-sphere bonding between $\mathrm{Fe}^{\mathrm{III}}$ and $\mathrm{SO}_{4}{ }^{2-}$ as has recently been suggested by Wang et al. 667 (2015) during the formation of schwertmannite.

668 A $\mu$-oxo dimer (Figure 3a) was calculated here as the thermodynamically most stable structure 669 (Table 1), in agreement with Yang et al. (2013) and Zhu et al. (2013) but contrasting to results 670 obtained elsewhere (Lopes et al., 2002; Panina et al., 2010). Experimental evidence for bonding 671 between a bridging $\mathrm{O}$ atom included: i) detection of a short $\mathrm{Fe}-\mathrm{O}$ interatomic distance during two 672 shell modelling of the first coordination shell of the $\mathrm{Fe}\left(\mathrm{ClO}_{4}\right)_{3}$ solution; ii) the trend in increasing 673 average Fe-O interatomic distances during hydrolysis, as suggested by its DFT-optimized structure, 674 and; iii) a concurrent increase in absorption of the high energy peak of the pre-edge region (Zhu et al. 675 2013). An increase in absorption of the high energy peak has been related to $\mu$-oxo bonding in 676 octahedral $\mathrm{Fe}^{\mathrm{III}}$ dimers (Westre et al., 1997) where it was postulated that the shorter Fe-O interatomic 
distances in the $\mathrm{Fe}-\mathrm{O}-\mathrm{Fe}$ bonds allowed for greater $4 \mathrm{p}$ mixing into the $3 \mathrm{~d}$ orbitals, and thus increased absorption intensity. Westre et al. (1997) also suggested that increasing bond covalency should manifest as an increase in intensity of the higher energy peak. Clearly $\mathrm{Fe}-\mathrm{OH}$ or $\mathrm{Fe}-\mathrm{O}$ bonding is more covalent than $\mathrm{Fe}-\mathrm{OH}_{2}$ and such an interpretation is, therefore, consistent with the trends observed in the XANES edge region (section 3.4.2).

682 These results strongly support the conclusions of Zhu et al. (2013) on the bonding topology of the $683 \mathrm{Fe}^{\mathrm{III}}$ dimer species. However, one of the main differences between the DFT optimized structures of 684 the dimer obtained here and elsewhere (Panina et al., 2010; Yang et al., 2013; Zhu et al., 2013) is the 685 Fe-O-Fe bond angle, and hence the Fe-Fe interatomic distance. Previously, it has been reported that this angle is approximately $180^{\circ}$ in accord with the angle observed for our in vacuo calculations (data not shown) and those of Yamaguchi and Ohira (2015), whereas use of the COSMO dielectric continuum solvation model during structural optimizations resulted in a reduction of this angle to $145^{\circ}$ (Figure 3a), similar to a dimer isolated from Nafion membranes (Pan et al., 1983). Recent DFT calculations using a polarizable continuum model to account for solvation effects also reported an Fe-O-Fe angle of $157^{\circ}$ (Yamaguchi and Ohira, 2015). As a neighboring Fe atom at $\sim 3.50 \AA$ (Table 2 and Yamaguchi and Ohira, 2015) or 3.61 (Yang et al., 2013; Zhu et al., 2013) could not be modelled, confirmation of either angle was not obtained. A lack of XAS evidence for a neighboring Fe atom at $\sim 3.60$ also makes it difficult to experimentally confirm the formation of a trimer based on its DFT-optimized structure.

696 It should be noted, however, that Zhu et al. (2013) observed that the UV-vis spectrum of their solution containing dimers was blue shifted compared to literature presented on a linear $\mathrm{Fe}-\mathrm{O}-\mathrm{Fe} \mathrm{Fe}-$ crown dimer (Junk et al., 2002), suggestive that the dimer species may not have a linear Fe-O-Fe bond.

\subsection{Effects of sulfate on polymerization pathways}

For the $\mathrm{Fe}_{2}\left(\mathrm{SO}_{4}\right)_{3}$ solution it appears that double corner-sharing between $\mathrm{Fe}^{\mathrm{III}}$ atoms is inhibited during hydrolysis, resulting in a $\mathrm{CN}$ at this interatomic distance that is approximately half that of the other solutions once precipitation was complete (Figure 6). Recently it has been shown that the sulfate inner-sphere complex in schwertmannite is likely to be bidendate-binuclear (Wang et al., 2015) (i.e. double corner-bonded) and the results obtained here, therefore, support this conclusion. Under the experimental conditions examined here, the complexation of $\mathrm{Fe}^{\mathrm{III}}$ by the $\mathrm{SO}_{4}{ }^{2-}$ anion also prevented the formation of the u-oxo dimer. It has recently been reported that the structural reconfiguration of this dimer is the rate-limiting step involved in the nucleation of ferrihydrite at high 
$710 \mathrm{Fe}^{\mathrm{III}}$ concentrations and acidic $\mathrm{pH}$ values (Zhu et al., 2016). If this were correct, then this 711 thermodynamic barrier would be removed in the presence of sulfate and so ferrihyfrite would be 712 expected to precipitate. As this was not the case, it is more likely that the presence of sulfate favors 713 the precipitation of schwertmannite due to double corner bonding with adjacent FeIII atoms existing 714 as either aqueous molecules or solid phase polymers. Given the important role of schwertmannite in 715 the retention of many inorganic contaminants in acid mine drainage and acid sulfate environments 716 (Regenspurg and Peiffer, 2005), insights into the pathways through which this mineral forms will 717 further our understaninding of how these elements can be structurally accommodated during 718 schwertmannite precipitation. For example, in contrast to the study of Zhu et al. (2012), the 719 experimental conditions of our potentiometric study did not result in the formation of ferrihydrite and 720 its subsequent transformation to schwertmannite but, rather, resulted in the direct formation of 721 schwertmannite, as originally proposed by Schwertmann et al. (1999).

722 The inhibition of double corner-sharing between $\mathrm{Fe}^{\mathrm{III}}$ atoms has also been previously observed 723 during $\mathrm{Fe}^{\mathrm{III}}$ hydrolysis and precipitation in the presence of other tetrahedral oxyanions, such as 724 silicate (Doelsch et al., 2000; Jones et al., 2009; Pokrovski et al., 2003; Voegelin et al., 2010), 725 phosphate (Rose et al., 1996; Voegelin et al., 2010) and arsenate (Maillot et al., 2013; Waychunas et 726 al., 1993) where it has generally been proposed that these tetrahedral oxyanions block double corner 727 bonding between $\mathrm{Fe}^{\mathrm{III}}$ octahedra (Pokrovski et al., 2003). However, if this distance is also 728 representative of tetrahedral $\mathrm{Fe}^{\mathrm{III}}$ in ferrihydrite (Maillot et al., 2011; Michel et al., 2007a), then a 729 decrease in the number of Fe backscatterers could also represent a loss of double corner bonding $\mathrm{Fe}^{\mathrm{III}}$ 730 tetrahedra.

731 Although trends $2 \mathrm{~b}$ and 3 in Figure 8 for the $\mathrm{Fe}\left(\mathrm{NO}_{3}\right)_{3}$ and $\mathrm{Fe}\left(\mathrm{ClO}_{4}\right)_{3}$ solutions have often been 732 attributed to the presence of tetrahedral or pentahedral $\mathrm{Fe}^{\mathrm{III}}$ within an octahedrally-dominated matrix 733 (Mikutta, 2011; Pokrovski et al., 2003; Zhao et al., 1994; Zhao et al., 1993), for this to be the case in 734 the present experiments, the related decrease in peak width of the high energy peak (trend 2a in 735 Figure 8) can only be interpreted as octahedral $\mathrm{Fe}$ becoming less distorted (and thus losing 736 absorption intensity) to a similar state as $\mathrm{Fe}^{\mathrm{III}}$ at an $\mathrm{OH}: \mathrm{Fe}$ ratio of 0. Westre et al. (1997) also noted 737 that the energy difference between the two pre-edge peaks of monomeric $\mathrm{Fe}^{\mathrm{III}}$ in octahedral geometry 738 can vary by as much as $0.4 \mathrm{eV}$, depending on ligation, which they related to ligand field strength. As 739 such, trends $2 \mathrm{a}$ and $2 \mathrm{~b}$ observed for the $\mathrm{Fe}\left(\mathrm{ClO}_{4}\right)_{3}$ and $\mathrm{Fe}\left(\mathrm{NO}_{3}\right)_{3}$ solutions in Figure 8 also have a 740 contribution from a decrease in ligand field strength in the first coordination shell bonding, which is 741 coincident with the onset of significant polymerization. Indeed, we speculate that if polymerization 742 is precursory to crystallization, and if long-range crystalline order moves the electronic structure of 743 the system from molecule-like to crystal-like, then more continuous waves through the solid will 
occur yielding more shared interactions that could decrease the local ligand field strength by "smearing out" electron density along a lattice. Therefore, the experimental evidence presented in

746 Figure 8 indicates that the increase in pre-edge intensity observed for the solid phases (trend 3) most likely results from a combination of decreased ligand field strength and the presence of tetrahedral $\mathrm{Fe}^{\mathrm{III}}$ in an octahedrally-dominated matrix where ferrihydrite precipitates. These results also provide experimental evidence for the recent suggestion of Zhu et al. (2016) that the assimilation of tetrahedral $\mathrm{Fe}^{\mathrm{III}}$ into ferrihydrite occurs at the latter stages of polymerization.

\section{CONCLUSIONS}

753 The experimental conditions employed in this XAS study, principally the high Fe $\mathrm{F}^{\mathrm{III}}$ concentrations, 754 are relevant to most studies that have examined the reactivity and structure of synthetically-prepared $755 \mathrm{Fe}^{\mathrm{III}}$ oxyhydroxides, such as 2-line ferrihydrite and schwertmannite (Cornell and Schwertmann, 756 2003).

757 Thermodynamic equilibrium speciation calculations implied that the aqueous speciation of $\mathrm{Fe}^{\mathrm{III}}$ 758 would be relatively simple during the potentiometric experiments with $\mathrm{Fe}\left(\mathrm{H}_{2} \mathrm{O}\right)_{6}{ }^{3+}$, the dimer/trimer 759 and the inner-sphere complexes with the counter anions comprising > $95 \%$ of the species present 760 (section 3.1). This relative simplicity was expressed in the spectral trends of the XAS data.

761 Density functional theory calculations in indicated that the $\mu$-oxo dimer is thermodynamically most 762 stable and XAS evidence for this species was obtained through one- and two-shell modelling of the 763 Fe-O coordination shell as well as characteristic trends produced in the pre-edge region during 764 hydrolysis. The DFT optimizations performed with the COSMO solvation model suggest that this 765 species has an Fe-Fe interatomic distance at least $0.11 \AA$ shorter than previously suggested. In 766 addition, the thermodynamically most stable $\mathrm{Fe}\left(\mathrm{H}_{2} \mathrm{O}\right)_{4}(\mathrm{Cl})_{2}{ }^{+}$complex was calculated to have the $\mathrm{Cl}$ 767 atoms in the cis position and there was good agreement between theoretically and experimentally 768 determined $\mathrm{Fe}-\mathrm{Cl}$ bond distances.

769 Multiple scattering pathways and trends in the average bond distance of the Fe-O coordination shell 770 for the $\mathrm{Fe}_{2}\left(\mathrm{SO}_{4}\right)_{3}$ during the initial stages of hydrolysis support the presence of thermodynamically 771 stable inner-sphere $\mathrm{Fe}^{\mathrm{III}}-\mathrm{SO}_{4}$ aqueous complexes, as predicted from thermodynamic equilibrium 772 calculations and Gibbs free energy differences calculated for DFT-optimized structures. The 773 presence of sulfate inhibits the formation of the dimer species as well as double corner-bonding of 774 octahedral/tetrahedral $\mathrm{Fe}^{\mathrm{III}}$. At the same time, edge-sharing $\mathrm{Fe}$ polymerization is promoted and the 775 formation of schwertmannite becomes thermodynamically favorable.

776 The initial stages of polymerization were evident in Fe-Fe interatomic distances at $\sim 3.04 \AA$. While 777 this is similar to the interatomic distance for the edge-sharing Fe atoms in the trimer, no evidence 
was obtained for the double corner Fe atom at $\sim 3.60 \AA$. Though it would be expected to be more difficult to detect this distance through EXAFS modelling (due to its longer R), the structure of the trimer, unlike the dimer, does not have other unique XAS spectral features for which its presence could be confirmed. As such, the existence of this species remains speculative.

The decomposition/transformation of the dimer was broadly coincident with extended polymerization and, in particular, statistically significant proportions of Fe backscatters at $\sim 3.43 \AA$ and a pre-edge energy transformation suggestive of decreased ligand field strength and the incorporation of tetrahedral $\mathrm{Fe}^{\mathrm{III}}$ into ferrihydrite.

\section{ELECTRONIC ANNEX}

Supplementary data (Tables A1-A7 and Figures A1-A15) associated with this article can be found in the Electronic Annex.

\section{ACKNOWLEDGEMENTS}

Richard Collins is a recipient of an Australian Research Council Future Fellowship (FT110100067) and also acknowledges the support of the Australian-American Fulbright Commission for a Senior Scholarship in Nuclear Science and Technology to work at Pacific Northwest National Laboratory. Kevin Rosso gratefully acknowledges the U.S. Department of Energy's (DOE) Office of Basic Energy Sciences, Chemical Sciences, Geosciences, \& Biosciences (CSGB) Division for support through the Geosciences program at Pacific Northwest National Laboratory (PNNL). Andrew Rose is a recipient of an Australian Research Council QEII Fellowship (DP0987351). Funding support was also provided by the Australian Research Council project DP120103234. The DFT calculations were performed using either EMSL, a national scientific user facility sponsored by the U.S. DOE Office of Biological and Environmental Research and located at PNNL or the Leonardi Engineering Research Computing Cluster, UNSW Australia.

\section{REFERENCES}

Apted, M.J., Waychunas, G.A. and Brown, G.E. (1985) Structure and specification of iron complexes in aqueous solutions determined by X-ray absorption spectroscopy. Geochim. Cosmochim. Acta 49, 2081-2089.

Arnek, R. and Schlyter, K. (1968) Thermochemical studies of hydrolytic reactions 7. A recalculation of calorimeter data on iron(III) hydrolysis. Acta Chemica Scandinavica 22, 1327-1330.

Becke, A.D. (1993) Density-functional thermochemistry .3. The role of exact exchange. Journal of Chemical Physics 98, 5648-5652. 
815 Boland, D.D., Collins, R.N., Glover, C.J. and Waite, T.D. (2013) An in situ quick-EXAFS and redox 816 potential study of the Fe(II)-catalysed tranformation of ferrihydrite. Colloids and Surfaces A: 817 Physicochemical and Engineering Aspects 435, 2-8.

818 Bottero, J.Y., Manceau, A., Villieras, F. and Tchoubar, D. (1994) Structure and mechanisms of 819 formation of $\mathrm{FeOOH}(\mathrm{Cl})$ polymers. Langmuir 10, 316-319.

820 Bunker, G. (1983) Application of the ratio method of EXAFS analysis to disordered systems. 821 Nuclear Instruments and Methods 207, 437-444.

822 Cardile, C.M. (1988) Tetrahedral $\mathrm{Fe}^{3+}$ in ferrihydrite: ${ }^{57} \mathrm{Fe}$ Mossbauer spectroscopic evidence. Clays 823 Clay Mineral 36, 537-539.

824 Chaboy, J., Munoz-Paez, A., Merkling, P.J. and Sanchez Marcos, E. (2006) The hydration of $\mathrm{Cu}^{2+}$ : 825 can the Jahn-Teller effect be detected in liquid solution? J. Chem. Phys. 124, Article No. 064509.

826 Collins, R.N., Bakkaus, E., Carriere, M., Khodja, H., Proux, O., Morel, J.-L. and Gouget, B. (2010) 827 Uptake, localization, and speciation of cobalt in Triticum aestivum L. (wheat) and Lycopersicon esculentum M. (tomato). Environ. Sci. Technol. 44, 2904-2910.

Combes, J.M., Manceau, A., Calas, G. and Bottero, J.Y. (1989) Formation of ferric oxides from aqueous solutions: a polyhedral approach by X-ray absorption spectroscopy: I. Hydrolysis and formation of ferric gels. Geochim. Cosmochim. Acta 53, 583-594.

Cornell, R.M. and Schwertmann, U. (2003) The iron oxides. Structures, properties, reactions, occurences and uses., 2nd Edition ed. Wiley-VCH Verlag GmbH \& Co. KGaA, Weinheim, Germany.

Cowley, J.M., Janney, D.E., Gerkin, R.C. and Buseck, P.R. (2000) The strucutre of ferritin cores determined by electron nanodiffraction. J. Structural Biol. 131, 210-216.

Dalba, G. and Fornasini, P. (1997) EXAFS Debye-Waller factor and thermal vibrations of crystals. Journal of Synchrotron Radiation 4, 243-255.

de Abreu, H.A., Guimaraes, L. and H.A., D. (2006) Density-functional theory study of firon(III) hydrolysis in aqueous solution. J. Phys. Chem. A 110, 7713-7718.

De Grave, E., Vandenberghe, R.E. and Dauwe, C. (2005) ILEEMS: methodology and applications to iron oxides. Hyperfine Interactions 161, 147-160.

DeWitt, J.G. (1992) X-ray absorption spectroscopic studies of the dinuclear iron center in methane monooxygenase and the sulfure and chlorine centers in photographic materials. Stanford University, CA, USA, Stanford.

Doelsch, E., Rose, J., Masion, A., Bottero, J.-Y., Nahon, D. and Bertsch, P.M. (2000) Speciation and crystal chemistry of iron(III) chloride hydrolyzed in the presence of $\mathrm{SiO}_{4}$ ligands. 1. An Fe K-edge EXAFS study. Langmuir 16, 4726-4731.

Downward, L., Booth, C.H., Lukens, W.W. and Bridges, F. (2007) A variation of the F-test for determining statistical relevance of particular parameters in EXAFS fits., in: Hedman, B., Pianetta, P. (Eds.), X-ray Absorbance Fine Structure - XAFS13: 13th International Conference, Stanford, CA, USA, pp. 129-131.

Drits, V.A., Sakharov, B.A., Salyn, A.L. and Manceau, A. (1993) Structural model for ferrihydrite. Clay Minerals 28, 185-207.

Eggleton, R.A. and Fitzpatrick, R.W. (1988) New data and a revised structural model for ferrihydrite. Clays Clay Mineral 36, 111-124.

Eggleton, R.A. and Fitzpatrick, R.W. (1990) New data and a revised structural model for ferrihydrite: reply. Clays Clay Mineral 38, 335-336.

Feller, D.J. (1996) The role of databases in support of computational chemistry calculations. Journal of Computational Chemistry 17, 1571-1586.

Fernandez-Martinez, A., Timon, V., Roman-Ross, G., Cuello, G.J., Daniels, J.E. and Ayora, C. (2010) The structure of schwertmannite, a nanocrystalline iron oxyhydroxysulfate. American Mineralogist 95, 1312-1322. 
864 Fernando, D.R., Mizuno, T., Woodrow, I.E., Baker, A.J.M. and Collins, R.N. (2010) 865 Characterisation of foliar $\mathrm{Mn}$ in Mn-(hyper)accumulators using X-ray absorption spectroscopy. New 866 Phytol. 188, 1014-1027.

867 Gray, H.B. (1971) Structural models for iron and copper proteins based on spectroscopic and 868 magnetic properties. Advances in Chemistry Series, 365-389.

Gualtieri, A. and Venturelli, P. (1999) In situ study of the goethite-hematite phase transformation by real time synchrotron powder diffraction. Am. Mineral. 84, 895-904.

Guyodo, Y., Sainctavit, P., Arrio, M.-A., Carvallo, C., Lee Penn, R., Erbs, J.J., Forsberg, B.S., Morin, G., Maillot, F., Lagroix, F., Bonville, P., Wilhelm, F. and Rogalev, A. (2012) X-ray magnetic circular dichroism provides strong evidence for tetrahedral iron in ferrihydrite. Geochem. Geophys. Geosyst. 13, Q06Z44.

Harrington, R., Hausner, D.B., Xu, W., Bhandari, N., Michel, F.M.M., Brown Jr, G.E., Strongin, D.R. and Parise, J.B. (2011) Neutron pair distribution function study of two-line ferrihydrite. Environ. Sci. Technol. 45, 9883-9890.

Harrison, P.M., Fischbach, F.A., Hoy, T.G. and Haggis, G.H. (1967) Ferric oxyhydroxide core of ferritin. Nature 216, 1188-1190.

Hiemstra, T. and van Riemsdijk, W.H. (2009) A surface structural model for ferrihydrite I: Sites related to primary charge, molar mass, and mass density. Geochim. Cosmochim. Acta 73, 44234436.

Hill, P.S. and Schauble, E.A. (2008) Modeling the effects of bond environment on equilibrium iron isotope fractionation in ferric aquo-chloro complexes. Geochim. Cosmochim. Acta 72, 1939-1958.

Janney, D.E., Cowley, J.M. and Buseck, P.R. (2000) Structure of synthetic 2-line ferrihydrite by electron nanodiffraction. Am. Mineral. 85, 1180-1187.

Jones, A.M., Collins, R.N., Rose, J. and Waite, T.D. (2009) The effect of Si and NOM on the Fe(II)catalysed transformation and reactivity of Fe(III) minerals. Geochim. Cosmochim. Acta 73, 44094422.

Junk, P.C., McCool, B.J., Moubaraki, B., Murray, K.S., Spiccia, L., Cashion, J.D. and Steed, J.W. (2002) Utilization of crown ethers to stabilize the dinuclear u-oxo bridged iron(III) aqua ion, [(H2o)5Fe(-O)Fe(OH2)5]4. J. Chem. Soc., Dalton Trans., 1024-1029.

Katz, J.E., Zhang, X., Attenkofer, K., Chapman, K.W., Frandsen, C., Zarzycki, P., Rosso, K.M., Falcone, R.W., Waychunas, G.A. and Gilbert, B. (2012) Electron small polarons and their mobility in iron (oxyhydr)oxide nanoparticles. Science 337, 1200-1203.

Klamt, A. and Schuurmann, G. (1993) COSMO: a new approach to dielectric screening in solvents with explicit expressions for the screening energy and its gradient. Journal of the Chemical Society, Perkin Transactions 2, 799-805.

Knight, R.J. and Sylva, R.N. (1975) Spectrophotometric investigation of iron(III) hydrolysis in light and heavy water at $25^{\circ} \mathrm{C}$. Journal of Inorganic and Nuclear Chemistry 37, 779-783.

Kubicki, J.D. (2001) Self-consistent reaction field calculations of aqueous $\mathrm{Al}^{3+}, \mathrm{Fe}^{3+}$, and $\mathrm{Si}^{4+}$ : Calculated aqueous-phase deprotonation energies correlated with experimental $\ln \left(K_{\mathrm{a}}\right)$ and $\mathrm{p} K_{\mathrm{a}} . \mathrm{J}$. Phys. Chem. A 105, 8756-8762.

Li, J., Fisher, C.L., J.L., C., Bashford, D. and Noodleman, L. (1996) Calculation of redox potentials and $\mathrm{pKa}$ values of hydrated transition metal cations by a combined density functional and continuum dielectric theory. Inorg. Chem. 35, 4694-4702.

Lopes, L., de Laat, J. and Legube, B. (2002) Charge transfer of iron(III) monomeric and oligomeric aqua hydroxo complexes: Semiempirical investigation into photoactivity. Inorg. Chem. 41, $2505-$ 2517.

Magini, M. (1977) Structural relationships between colloidal solutions and hydroxide gels of iron(III) nitrate. J. Inorg. Nucl. Chem. 39, 409-412.

Magini, M. and Caminiti, R. (1977) On the structure of highly concentrated iron(III) salt solutions. J. Inorg. Nucl. Chem. 39, 91-94. 
914 Maillot, F., Morin, G., Juillot, F., Bruneel, O., Casiot, C., Ona-Nguema, G., Wang, Y., Lebrun, S., 915 Aubry, E., Vlaic, G. and Brown Jr., G.E. (2013) Structure and reactivity of As(III)- and As(V)-rich 916 schwertmannites and amorphous ferric arsenate sulfate from the Carnoules acid mine drainage, 917 France: Comparison with biotic and abiotic model compounds and implications for As remediation. 918 Geochim. Cosmochim. Acta 104, 310-329.

919 Maillot, F., Morin, G., Wang, Y., Bonnin, D., Ildefonse, P., Chaneac, C. and Calas, G. (2011) New 920 insight into the structure of nanocrystalline ferrihydrite: EXAFS evidence for tetrahedrally 921 coordinated iron(III). Geochimica et Cosmochimica Acta 75, 2708-2720.

922 Manceau, A. (2009) Evaluation of the structural model for ferrihydrite derived from real-space 923 modelling of high-energy X-ray diffraction data. Clay Minerals 44, 19-34.

Manceau, A. (2010) PDF analysis of ferrihydrite and the violation of Pauling's Principia. Clay Minerals 45, 225-228.

Manceau, A. (2011) Critical evaluation of the revised akdalaite model for ferrihydrite. Clay Minerals 45, 225-228.

Manceau, A., Combes, J.M. and Calas, G. (1990) New data and a revised structural model for ferrihydirte: comment. Clays Clay Mineral 38, 331-334.

Manceau, A. and Drits, V.A. (1993) Local structure of ferrihydrite and feroxyhite by EXAFS spectroscopy. Clay Minerals 28, 165-184.

Manceau, A. and Gates, W.P. (1997) Surface structural model for ferrihydrite. Clays Clay Mineral 45, 448-460.

Martin, R.L., Hay, P.J. and Pratt, L.R. (1998) Hydrolysis of ferric ion in water and conformational equilibrium. Journal of Physical Chemistry A 102, 3565-3573.

Michel, F.M., Barron, V., Torrent, J., Morales, M.P., Serna, C.J., Boily, J.-F., Liu, Q., Ambrosini, A., Cismasu, A.C. and Brown Jr., G.E. (2010) Ordered ferrimagnetic form of ferrihydrite reveals links among structure, composition, and magnetism. Proc. Natl. Ac. Sci. U.S.A. 107, 2787-2792.

Michel, F.M., Ehm, L., Antao, S.M., Lee, P.L., Chupas, P.J., Liu, G., Strongin, D.R., Schoonen, M.A.A., Phillips, B.L. and Parise, J.B. (2007a) The structure of ferrihydrite, a nanocrystalline material. Science 316, 1726-1729.

Michel, F.M., Ehm, L., Liu, G., Han, W.Q., Antao, S.M., Chupas, P.J., Lee, P.L., Knorr, K., Eulert, H., Kim, J., Grey, C.P., Celestian, A.J., Gillow, J., Schoonen, M.A.A., Strongin, D.R. and Parise, J.B. (2007b) Similarities in 2-and 6-line ferrihydrite based on pair distribution function analysis of X-ray total scattering. Chemistry of Materials 19, 1489-1496.

Mikutta, C. (2011) X-ray absorption spectroscopy study on the effect of hydroxybenzoic acids on the formation and structure of ferrihydrite. Geochim. Cosmochim. Acta 75, 5122-5139.

Milburn, R.M. and Vosburgh, W.C. (1955) A spectrophotometric study of the hydrolysis of iron(III) ion. II. Polynuclear species. Journal of the American Chemical Society 77, 1352-1355.

Mulay, L.N. and Selwood, P.W. (1955) Hydrolysis of $\mathrm{Fe}^{3+}$ : Magnetic and spectrophotometric studies on ferric perchlorate solutions. Journal of the American Chemical Society 77, 2693-2701.

Murad, E. (1988) The Bossbauer spectrum of "well"-crystallized ferrihydrite. J. Magnetism and Magnetic Materials 74, 153-157.

Murad, E. and Schwertmann, U. (1980) The Mossbauer spectrum of ferrihydrite and its relations to those of other iron oxides. Am. Mineral. 65, 1044-1049.

Ottonello, G. and Zuccolini, M.V. (2009) Ab-initio structure, energy and stable Fe isotope equilbrium fractionation of some geochemically relevant H-O-Fe complexes. Geochim. Cosmochim. Acta 73, 6447-6469.

Pan, H.K., Yarusso, D.J., Knapp, G.S., Pineri, M., Meagher, A., Coey, J.M.D. and Cooper, S.L. (1983) EXAFS and mossbauer studies of iron neutralized Nafion ionomers. J. Chem. Phys. 79, 4736. Pan, Y.-H., Vaughan, G., Brydson, R., Bleloch, A., Gass, M., Sader, K. and Brown, A. (2010) Electron-beam-induced reduction of $\mathrm{Fe}^{3+}$ in iron phosphate dihydrate, ferrihydrite, haemosiderin and ferritin as revealed by electron energy-loss spectroscopy. Ultramicroscopy 110, 1020-1032. 
964 Panina, N.S., Belyaev, A.N., Eremin, A.V. and Davidovich, P.B. (2010) DFT quantum-chemical 965 study of the hydrolysis products of $\mathrm{Fe}(\mathrm{II})$ and $\mathrm{Fe}(\mathrm{III})$ aqua-complexes. Russian Journal of General 966 Chemistry 80, 889-894.

967 Pankhurst, Q.A. and Pollard, R.J. (1992) Structural and magnetic properties of ferrihydrite. Clays 968 Clay Mineral 40, 268-272.

969 Perera, W.N. and Hefter, G. (2003) Mononuclear cyano- and hydroxo-complexes of iron(III). Inorg. 970 Chem. 42, 5917-5923.

971 Pham, A.N., Rose, A.L., Feitz, A.J. and Waite, T.D. (2006) Kinetics of Fe(III) precipitation in 972 aqueous solutions at $\mathrm{pH}$ 6.0-9.5 and $25{ }^{\circ} \mathrm{C}$. Geochim. Cosmochim. Acta 70, 640-650.

973 Pokrovski, G.S., Schott, J., Farges, F. and Hazemann, J.-L. (2003) Iron (III)-silica interactions in 974 aqueous solution: Insights from X-ray absorption fine structure spectroscopy. Geochim. Cosmochim. 975 Acta 67, 3559-3573.

976 Rancourt, D.G. and Meunier, J.-F. (2008) Constraints on structural models of ferrihydrite as a nanocrystalline material. Am. Mineral. 93, 1412-1417.

Ravel, B. and Newville, M. (2005) ATHENA, ARTEMIS, HEPHAESTUS: data analysis for X-ray absorption spectroscopy using IFEFFIT. Journal of Synchrotron Radiation 12, 537-541.

Regenspurg, S. and Peiffer, S. (2005) Arsenate and chromate incorporation in schwertmannite. Applied Geochemistry 20, 1226-1239.

Rose, A.L. and Waite, T.D. (2003) Kinetics of hydrolysis and precipitation of ferric iron in seawater. Environnmental Science \& Technology 37, 3897-3903.

Rose, J., Manceau, A., Bottero, J.-Y., Masion, A. and Garcia, F. (1996) Nucleation and growth mechanisms of $\mathrm{Fe}$ oxyhydroxide in the presence of $\mathrm{PO}_{4}$ ions. 1. Fe K-edge EXAFS study. Langmuir 12, 6701-6707.

Rose, J., Manceau, A., Masion, A. and Bottero, J.Y. (1997) Structure and mechanisms of formation of $\mathrm{FeOOH}\left(\mathrm{NO}_{3}\right)$ oligmers in the early stages of hydrolysis. Langmuir 13, 3240-3246.

Sarangi, R. (2013) X-ray absorption near-edge spectrsocopy in bioinorganic chemistry: Application to $\mathrm{M}-\mathrm{O}_{2}$ systems. Coordin. Chem. Rev. 257, 459-472.

Schuchardt, K.L., Didier, B.T., Elsethagen, T., Sun, L., Gurumoorthi, V., Chase, J., Li, J. and Windus, T.L. (2007) Basis set exchange: A community database for computational sciences. Journal of Chemical Information and Modeling 47, 1045-1052.

Schwertmann, U., Friedl, J. and Stanjek, H. (1999) From Fe(III) ions to ferrihydrite and then to hematite. J. Colloid Interf. Sci. 209, 215-223.

Shulman, R.G., Yafet, Y., Eisenberger, P. and Blumberg, W.E. (1976) Observation and interpretation of X-ray absorption edges in iron compounds and proteins. Proc. Natl. Ac. Sci. U.S.A 73, 1384-1388. Sommer, B.A. and Margerum, D.W. (1970) Kinetic study of the hydroxoiron(III) dimer. Inorganic Chemistry 9, 2517-2521.

Toner, B.M., Santelli, C.M., Marcus, M.A., Wirth, R., Chan, C.S., McCollom, T., Bach, W. and Edwards, K.J. (2009) Biogenic iron oxyhydroxide formation at mid-ocean ridge hydrothermal vents: Juan de Fuca Ridge. Geochimica et Cosmochimica Acta 73, 388-403.

Towe, K.M. and Bradley, W.F. (1967) Mineralogical constitution of colloidal hydrous ferric oxides. J. Colloid Interface Sci. 24, 384-392.

Valiev, M., Bylaska, E.J., Govind, N., Kowalski, K., Straatsma, T.P., van Dam, H.J.J., Wang, D., Nieplocha, J., Apra, E., Windus, T.L. and de Jong, W.A. (2010) NWChem: a comprehensive and scalable open-source solution for large scale molecular simulations. Computer Physics Communications 181, 1477-1489.

Voegelin, A., Kaegi, R., Frommer, J., Vantelon, D. and Hug, S.J. (2010) Effect of phosphate, silicate, and $\mathrm{Ca}$ on $\mathrm{Fe}(\mathrm{III})$-precipitates formed in aerated $\mathrm{Fe}(\mathrm{II})$ - and $\mathrm{As}$ (III)-containing water studied by X-ray absorption spectroscopy. Geochim. Cosmochim. Acta 74, 164-186.

Wang, X., Gu, C., Feng, X. and Zhu, M. (2015) Sulfate local coordination environment in schwertmannite. Environ. Sci. Technol. 49, 10440-10448. 
1014 Waychunas, G.A., Fuller, C.C., Rea, B.A. and Davis, J.A. (1996) Wide angle X-ray scattering 1015 (WAXS) study of "two line"ferrihydrite structure: Effect of arsenate sorption and counterion 1016 variation and comparison with EXAFS results. Geochim. Cosmochim. Acta 60, 1765-1781.

1017 Waychunas, G.A., Rea, B.A., Fuller, C.C. and Davis, J.A. (1993) Surface chemistry of ferrihydrite: 1018 Part 1. EXAFS studies of the geometry of coprecipitated and adsorbed arsenate. Geochim. 1019 Cosmochim. Acta 57, 2251-2269.

1020 Westre, T.E., Kennepohl, P., DeWitt, J.G., Hedman, B., Hodgson, K.O. and Solomon, E.I. (1997) A 1021 multiplet analysis of Fe K-edge 1s 3d pre-edge features of iron complexes. Journal of the American 1022 Chemical Society 119, 6297-6314.

1023 Xu, W., Hausner, D.B., Harrington, R., Lee, P.L., Strongin, D.R. and Parise, J.B. (2011) Structural 1024 water in ferrihydrite and constraints this provides on possible structure models. Am. Mineral. 96, 1025 513-520.

1026 Yamaguchi, M. and Ohira, A. (2015) Density functional theory calculation of u-oxo and u-hydroxo 1027 bridged iron(III) aqua dimer complexes in perfluorinated sulfonic acid ionomer membranes. 1028 Computational and Theoretical Chemistry 1071, 61-67.

1029 Yang, Y., Ratner, M.A. and Schatz, G.C. (2013) Computational modeling of octahedral iron oxide 1030 clusters: hexaaquairon(III) and its dimers. J. Phys. Chem. C 117, 21706-21717.

1031 Zakharov, I.I., Kudjukov, K.Y., Bondar, V.V., Tyupalo, N.F. and Minaev, B.F. (2001) DFT-based 1032 thermodynamics of fento reactions rejects the 'pure' aquacomplex models. Computational and 1033 Theoretical Chemistry 964, 94-99.

1034 Zhao, J., Huggins, F.E., Feng, Z. and Huffman, G.P. (1994) Ferrihydrite: Surface structure and its 1035 effects on phase transformation. Clays Clay Mineral 42, 737-746.

1036 Zhao, J., Huggins, F.E., Feng, Z., Lu, F., Shah, N. and Huffman, G.P. (1993) Structure of a 1037

1038

1039

1040

1041

1042

1043

1044

1045 nanophase iron oxide catalyst. Journal of Catalysis 143, 499-509.

Zhu, M., Frandsen, C., Wallace, A.F., Legg, B., Khalid, S., Zhang, H., Morup, S., Banfield, J.F. and Waychunas, G.A. (2016) Precipitation pathways for ferrihydrite formation in acidic solutions. Geochimica et Cosmochimica Acta 172, 247-264.

Zhu, M., Legg, B., Zhang, H., Gilbert, B., Ren, Y., Banfield, J.F. and Waychunas, G.A. (2012) Early stage formation of iron oxyhydroxides during neutralization of simulated acid mine drainage solutions. Environ. Sci. Technol. 46, 8140-8147.

1046 1047

Zhu, M., Puls, B.W., Frandsen, C., Kubicki, J.D., Zhang, H. and Waychunas, G.A. (2013) In situ structural characterization of ferric iron dimers in aqueous solutions: identification of u-oxo species. Inorganic Chemistry 52, 6788-6797. 


\section{FIGURE CAPTIONS}

1049 Figure 1: Thermodynamic equilibrium speciation $\left(25^{\circ} \mathrm{C}\right.$, atm. pressure $)$ of $\mathrm{Fe}^{\mathrm{III}}$ as a function of $\mathrm{pH}$ 1050 for the various salt solutions with (a) inclusion and (b) exclusion of the trimer. Coordinated water 1051 molecules have been omitted for simplicity. Details on how these calculations were performed are 1052 provided in section 2.1 .

1054 Figure 2: DFT optimized structures and $\mathrm{Fe}-\mathrm{O} / \mathrm{Cl}$ bond distances $(\AA)$ of the thermodynamically most 1055 stable aqueous monomeric $\mathrm{Fe}^{\mathrm{III}}$ species shown in Figure 1. a) $\mathrm{Fe}\left(\mathrm{H}_{2} \mathrm{O}\right)_{6}{ }^{3+}$, b) $\mathrm{Fe}\left(\mathrm{ClO}_{4}\right)\left(\mathrm{H}_{2} \mathrm{O}\right)_{5}{ }^{2+}$, c) $1056 \mathrm{Fe}\left(\mathrm{NO}_{3}\right)\left(\mathrm{H}_{2} \mathrm{O}\right)_{5}{ }^{2+}$, d) $\mathrm{Fe}\left(\mathrm{SO}_{4}\right)\left(\mathrm{H}_{2} \mathrm{O}\right)_{4}{ }^{+}$, e) $\mathrm{Fe}\left(\mathrm{SO}_{4}\right)_{2}\left(\mathrm{H}_{2} \mathrm{O}\right)_{2}{ }^{-}$, f) $\mathrm{Fe}(\mathrm{Cl})\left(\mathrm{H}_{2} \mathrm{O}\right)_{5}{ }^{2+}$ and g) cis$1057 \mathrm{Fe}(\mathrm{Cl})_{2}\left(\mathrm{H}_{2} \mathrm{O}\right)_{4}{ }^{+}$.

1059 Figure 3: DFT optimized structures, and Fe- $\mathrm{OH}_{2}$ bond distances $(\AA)$, of the thermodynamically most 1060 stable Fe ${ }^{\mathrm{III}}$ dimeric (a) and trimeric (b) hydrolysis species.

1062 Figure 4: Phase uncorrected Fourier-transformed EXAFS spectra (left) and difference spectra (right) 1063 during $\mathrm{Fe}^{\mathrm{III}}$ hydrolysis and precipitation in the four solutions ( $\mathrm{k}$ range $=2-12 \AA^{-1}$ ). Hydrolysis 1064 increases from the red spectrum through to the grey spectra. The difference spectra represent the 1065 difference to the first spectrum. The corresponding EXAFS spectra are provided in Figure A3.

1067 Figure 5: Average Fe-O interatomic distance, coordination number $(\mathrm{CN})$, and Debye-Waller factor $1068\left(\sigma^{2}\right)$ as a function of $\mathrm{pH}_{\mathrm{F}}$ and $\mathrm{OH}: \mathrm{Fe}$ ratio $\left(\mathrm{Fe}\left(\mathrm{ClO}_{4}\right)_{3}=\right.$ blue diamonds, $\mathrm{Fe}\left(\mathrm{NO}_{3}\right)_{3}=$ red squares, $1069 \mathrm{FeCl}_{3}=$ black circles and $\mathrm{Fe}_{2}\left(\mathrm{SO}_{4}\right)_{3}=$ green triangles). The CNs for the first four data points of the $1070 \mathrm{FeCl}_{3}$ solution are the sum of the $\mathrm{CN}$ for the $\mathrm{Fe}-\mathrm{O}$ and $\mathrm{Fe}-\mathrm{Cl}$ pathways. The other parameters shown 1071 are only those for the Fe-O pathway. The $\mathrm{CNs}$ shown for the $\mathrm{Fe}_{2}\left(\mathrm{SO}_{4}\right)_{3}$ solution were not 1072 significantly different from 6. Full modelling results and fits are provided in, respectively, Tables 1073 A4-A7 and Figures A6-A9.

1075 Figure 6: Average $\mathrm{Fe}-\mathrm{Fe}$ interatomic distance and coordination number $(\mathrm{CN})$ as a function of $\mathrm{pH}_{\mathrm{F}}$ 1076 and $\mathrm{OH}: \mathrm{Fe}$ ratio $\left(\mathrm{Fe}\left(\mathrm{ClO}_{4}\right)_{3}=\right.$ blue diamonds, $\mathrm{Fe}\left(\mathrm{NO}_{3}\right)_{3}=$ red squares, $\mathrm{FeCl}_{3}=$ black circles and $1077 \mathrm{Fe}_{2}\left(\mathrm{SO}_{4}\right)_{3}=$ green triangles). Full modelling results and fits are provided in, respectively, Tables 1078 A4-A7 and Figures A6-A9.

1080 Figure 7: a) XANES spectra during $\mathrm{Fe}^{\mathrm{III}}$ hydrolysis and precipitation in the four solutions. 1081 Hydrolysis increases from the red spectrum through to the grey spectra. The relevance of the energy 
1082 regions marked from $\mathrm{A}$ to $\mathrm{E}$ is discussed in section 3.3.5; b) Pre-edge features, marked as $\mathrm{E}$ in Figure $10837 \mathrm{a}$, enlarged for clarity.

1084

1085 Figure 8: Normalized and background (white-line) subtracted pre-edge features of the four solutions.

1086 The labelled arrows represent trends in the spectra which are discussed in section 3.4.3. Hydrolysis 1087 increases from the red spectrum through to the grey spectra. 
Table 1: Calculated Gibbs free energy $(\mathrm{kJ} / \mathrm{mol})$ of $\mathrm{Fe}^{\mathrm{III}}$ hydrolysis and complexation pathways in aqueous solution at $T=298.15 \mathrm{~K}$ and $p=1 \mathrm{~atm}$. Reactions in bold highlight the thermodynamically most stable reaction products that form from hydrolysis or complexation and whose structures are shown in Figures 2 and 3. The Gibbs free energy of $\mathrm{H}^{+}$was sourced from (Zhan and Dixon, 2001).

\begin{tabular}{|c|c|}
\hline Reaction & $\Delta G_{298.15(\mathrm{aq})}$ \\
\hline \multicolumn{2}{|l|}{ Inorganic complexation } \\
\hline $\mathrm{Fe}\left(\mathrm{H}_{2} \mathrm{O}\right)_{6}{ }^{3+}+\mathrm{ClO}_{4}^{-} \rightarrow \mathrm{Fe}\left(\mathrm{H}_{2} \mathrm{O}\right)_{5}\left(\mathrm{ClO}_{4}\right)^{2+}+\mathrm{H}_{2} \mathrm{O}$ & -23.4 \\
\hline $\mathrm{Fe}\left(\mathrm{H}_{2} \mathrm{O}\right)_{6}{ }^{3+}+\mathrm{ClO}_{4}{ }^{-} \rightarrow$ outersphere $-\mathrm{Fe}\left(\mathrm{H}_{2} \mathrm{O}\right)_{6}\left(\mathrm{ClO}_{4}\right)^{2+}$ & 37.2 \\
\hline $\mathrm{Fe}\left(\mathrm{H}_{2} \mathrm{O}\right)_{6}{ }^{3+}+\mathrm{NO}_{3}^{-} \rightarrow \mathrm{Fe}\left(\mathrm{H}_{2} \mathrm{O}\right)_{5}\left(\mathrm{NO}_{3}\right)^{2+}+\mathrm{H}_{2} \mathrm{O}$ & -64.0 \\
\hline $\mathrm{Fe}\left(\mathrm{H}_{2} \mathrm{O}\right)_{6}{ }^{3+}+\mathrm{NO}_{3}{ }^{-} \rightarrow$ outersphere- $\mathrm{Fe}\left(\mathrm{H}_{2} \mathrm{O}\right)_{5}(\mathrm{OH})\left(\mathrm{HNO}_{3}\right)^{2+}$ & 25.9 \\
\hline $\mathrm{Fe}\left(\mathrm{H}_{2} \mathrm{O}\right)_{6}{ }^{3+}+\mathrm{Cl}^{-} \rightarrow \mathrm{Fe}\left(\mathrm{H}_{2} \mathrm{O}\right)_{5} \mathrm{Cl}^{2+}+\mathrm{H}_{2} \mathrm{O}$ & -116.6 \\
\hline $\mathrm{Fe}\left(\mathrm{H}_{2} \mathrm{O}\right)_{6}{ }^{3+}+\mathrm{Cl}^{-} \rightarrow$ outersphere- $\mathrm{Fe}\left(\mathrm{H}_{2} \mathrm{O}\right)_{6} \mathrm{Cl}^{2+}$ & -29.7 \\
\hline $\mathrm{Fe}\left(\mathrm{H}_{2} \mathrm{O}\right)_{6}{ }^{3+}+2 \mathrm{Cl}^{-} \rightarrow c i s-\mathrm{Fe}\left(\mathrm{H}_{2} \mathrm{O}\right)_{4}(\mathrm{Cl})_{2}{ }^{+}+2 \mathrm{H}_{2} \mathrm{O}$ & -231.1 \\
\hline $\mathrm{Fe}\left(\mathrm{H}_{2} \mathrm{O}\right)_{6}{ }^{3+}+2 \mathrm{Cl}^{-} \rightarrow$ trans $-\mathrm{Fe}\left(\mathrm{H}_{2} \mathrm{O}\right)_{4}(\mathrm{Cl})_{2}{ }^{+}+2 \mathrm{H}_{2} \mathrm{O}$ & -220.4 \\
\hline $\mathrm{Fe}\left(\mathrm{H}_{2} \mathrm{O}\right)_{6}{ }^{3+}+\mathrm{SO}_{4}{ }^{2-} \rightarrow \mathrm{Fe}\left(\mathrm{H}_{2} \mathrm{O}\right)_{4}\left(\mathrm{SO}_{4}\right)^{+}+2 \mathrm{H}_{2} \mathrm{O}$ & -227.0 \\
\hline $\mathrm{Fe}\left(\mathrm{H}_{2} \mathrm{O}\right)_{6}{ }^{3+}+\mathrm{SO}_{4}{ }^{2-} \rightarrow \mathrm{Fe}\left(\mathrm{H}_{2} \mathrm{O}\right)_{4}(\mathrm{OH})\left(\mathrm{HSO}_{4}\right)^{+}+\mathrm{H}_{2} \mathrm{O}$ & -193.6 \\
\hline $\mathrm{Fe}\left(\mathrm{H}_{2} \mathrm{O}\right)_{6}{ }^{3+}+\mathrm{SO}_{4}{ }^{2-} \rightarrow$ outersphere $-\mathrm{Fe}\left(\mathrm{H}_{2} \mathrm{O}\right)_{5}(\mathrm{OH})\left(\mathrm{HSO}_{4}\right)^{+}$ & -140.0 \\
\hline $\mathrm{Fe}\left(\mathrm{H}_{2} \mathrm{O}\right)_{6}{ }^{3+}+2 \mathrm{SO}_{4}{ }^{2-} \rightarrow \mathrm{Fe}\left(\mathrm{H}_{2} \mathrm{O}\right)_{2}\left(\mathrm{SO}_{4}\right)_{2}{ }^{-}+4 \mathrm{H}_{2} \mathrm{O}$ & -404.3 \\
\hline \multicolumn{2}{|l|}{ Hydrolysis (dimeric species, total charge $=+4$ ) } \\
\hline $2 \mathrm{Fe}\left(\mathrm{H}_{2} \mathrm{O}\right)_{6}{ }^{3+} \rightarrow \mathrm{Fe}\left(\mathrm{H}_{2} \mathrm{O}\right)_{5}-\mathrm{O}-\mathrm{Fe}\left(\mathrm{H}_{2} \mathrm{O}\right)_{5}{ }^{4+}+2 \mathrm{H}^{+}+\mathrm{H}_{2} \mathrm{O}$ & 6.1 \\
\hline $2 \mathrm{Fe}\left(\mathrm{H}_{2} \mathrm{O}\right)_{6}{ }^{3+} \rightarrow \mathrm{Fe}\left(\mathrm{H}_{2} \mathrm{O}\right)_{5}-\mathrm{O}-\mathrm{Fe}\left(\mathrm{H}_{2} \mathrm{O}\right)_{4}{ }^{4+}+2 \mathrm{H}^{+}+2 \mathrm{H}_{2} \mathrm{O}$ & $23.0^{\mathrm{a}}$ \\
\hline $2 \mathrm{Fe}\left(\mathrm{H}_{2} \mathrm{O}\right)_{6}{ }^{3+} \rightarrow \mathrm{Fe}\left(\mathrm{H}_{2} \mathrm{O}\right)_{4}-2 \mathrm{OH}-\mathrm{Fe}\left(\mathrm{H}_{2} \mathrm{O}\right)_{4}{ }^{4+}+2 \mathrm{H}^{+}+2 \mathrm{H}_{2} \mathrm{O}$ & 26.9 \\
\hline \multicolumn{2}{|l|}{ Hydrolysis (trimeric species, total charge $=+5$ ) } \\
\hline $3 \mathrm{Fe}\left(\mathrm{H}_{2} \mathrm{O}\right)_{6}{ }^{3+} \rightarrow$ double corner- $\mathrm{Fe}_{3}\left(\mathrm{H}_{2} \mathrm{O}\right)_{10}(\mathrm{OH})_{4}{ }^{5+}+4 \mathrm{H}^{+}+4 \mathrm{H}_{2} \mathrm{O}$ & -9.6 \\
\hline $3 \mathrm{Fe}\left(\mathrm{H}_{2} \mathrm{O}\right)_{6}{ }^{3+} \rightarrow$ linear $-\mathrm{Fe}_{3}\left(\mathrm{H}_{2} \mathrm{O}\right)_{14}(\mathrm{O})_{2}{ }^{5+}+4 \mathrm{H}^{+}+2 \mathrm{H}_{2} \mathrm{O}$ & -0.8 \\
\hline $3 \mathrm{Fe}\left(\mathrm{H}_{2} \mathrm{O}\right)_{6}{ }^{3+} \rightarrow$ linear $-\mathrm{Fe}_{3}\left(\mathrm{H}_{2} \mathrm{O}\right)_{12}(\mathrm{O})(\mathrm{OH})_{2}{ }^{5+}+4 \mathrm{H}^{+}+3 \mathrm{H}_{2} \mathrm{O}$ & 6.8 \\
\hline $3 \mathrm{Fe}\left(\mathrm{H}_{2} \mathrm{O}\right)_{6}{ }^{3+} \rightarrow$ single corner $-\mathrm{Fe}_{3}\left(\mathrm{H}_{2} \mathrm{O}\right)_{14}(\mathrm{O})_{2}{ }^{5+}+4 \mathrm{H}^{+}+2 \mathrm{H}_{2} \mathrm{O}$ & 11.4 \\
\hline $3 \mathrm{Fe}\left(\mathrm{H}_{2} \mathrm{O}\right)_{6}{ }^{3+} \rightarrow$ linear $-\mathrm{Fe}_{3}\left(\mathrm{H}_{2} \mathrm{O}\right)_{10}(\mathrm{OH})_{4}{ }^{5+}+4 \mathrm{H}^{+}+4 \mathrm{H}_{2} \mathrm{O}$ & 18.6 \\
\hline $3 \mathrm{Fe}\left(\mathrm{H}_{2} \mathrm{O}\right)_{6}{ }^{3+} \rightarrow$ single corner $-\mathrm{Fe}_{3}\left(\mathrm{H}_{2} \mathrm{O}\right)_{12}(\mathrm{O})(\mathrm{OH})_{2}{ }^{5+}+4 \mathrm{H}^{+}+3 \mathrm{H}_{2} \mathrm{O}$ & 35.9 \\
\hline $3 \mathrm{Fe}\left(\mathrm{H}_{2} \mathrm{O}\right)_{6}{ }^{3+} \rightarrow$ linear $-\mathrm{Fe}_{3}\left(\mathrm{H}_{2} \mathrm{O}\right)_{12}(\mathrm{O})_{2}{ }^{5+}+4 \mathrm{H}^{+}+4 \mathrm{H}_{2} \mathrm{O}$ & $70.1^{b}$ \\
\hline $3 \mathrm{Fe}\left(\mathrm{H}_{2} \mathrm{O}\right)_{6}{ }^{3+} \rightarrow$ linear $-\mathrm{Fe}_{3}\left(\mathrm{H}_{2} \mathrm{O}\right)_{12}(\mathrm{O})_{2}{ }^{5+}+4 \mathrm{H}^{+}+4 \mathrm{H}_{2} \mathrm{O}$ & $77.9^{c}$ \\
\hline $3 \mathrm{Fe}\left(\mathrm{H}_{2} \mathrm{O}\right)_{6}{ }^{3+} \rightarrow$ linear $-\mathrm{Fe}_{3}\left(\mathrm{H}_{2} \mathrm{O}\right)_{8}(\mathrm{OH})_{4}{ }^{5+}+4 \mathrm{H}^{+}+6 \mathrm{H}_{2} \mathrm{O}$ & $82.1^{\mathrm{c}}$ \\
\hline $3 \mathrm{Fe}\left(\mathrm{H}_{2} \mathrm{O}\right)_{6}{ }^{3+} \rightarrow$ double corner $-\mathrm{Fe}_{3}\left(\mathrm{H}_{2} \mathrm{O}\right)_{8}(\mathrm{OH})_{4}{ }^{5+}+4 \mathrm{H}^{+}+6 \mathrm{H}_{2} \mathrm{O}$ & $101.3^{\mathrm{d}}$ \\
\hline
\end{tabular}

\footnotetext{
${ }^{\mathrm{a}}$ One $\mathrm{Fe}$ atom penta-coordinated.

${ }^{\mathrm{b}}$ End Fe atoms penta-coordinated.

${ }^{\mathrm{c}}$ Central Fe atom tetra-coordinated.

${ }^{\mathrm{d}}$ Double corner-bonded Fe atom tetra-coordinated.
} 
Table 2: Interatomic distances for the DFT-optimized structures of the thermodynamically most stable Fe ${ }^{\text {III }}$ aqueous species and for the ferrihydrite and schwertmannite structures proposed by, respectively, Michel et al. (2007a) and Fernandez-Martinez et al. (2010).

\begin{tabular}{|c|c|c|c|c|c|}
\hline Species & & Inte & tomic distance & $(\AA)$ & \\
\hline & $\mathrm{Fe}-\mathrm{OH}_{2}$ & Fe-OH/Anion & $\mathrm{Fe}-\mathrm{O}$ & Average $\mathrm{Fe}-\mathrm{O}$ & $\mathrm{Fe}-\mathrm{Fe}$ \\
\hline Hydrolysis (monomeric species) & & & & & \\
\hline $\mathrm{Fe}\left(\mathrm{H}_{2} \mathrm{O}\right)_{6}{ }^{3+}$ & $2.015 \pm 0.002$ & & & $2.015 \pm 0.002$ & \\
\hline Inorganic complexes & & & & & \\
\hline $\mathrm{Fe}\left(\mathrm{H}_{2} \mathrm{O}\right)_{5}\left(\mathrm{ClO}_{4}\right)^{2+}$ & $2.035 \pm 0.026$ & 1.944 & & $2.020 \pm 0.044$ & \\
\hline $\mathrm{Fe}\left(\mathrm{H}_{2} \mathrm{O}\right)_{5}\left(\mathrm{NO}_{3}\right)^{2+}$ & $2.039 \pm 0.032$ & 1.940 & & $2.023 \pm 0.050$ & \\
\hline $\mathrm{Fe}\left(\mathrm{H}_{2} \mathrm{O}\right)_{5} \mathrm{Cl}^{2+}$ & $2.066 \pm 0.030$ & 2.215 & & $2.091 \pm 0.067^{\mathrm{a}}$ & \\
\hline cis- $\mathrm{Fe}\left(\mathrm{H}_{2} \mathrm{O}\right)_{4}(\mathrm{Cl})_{2}^{+}$ & $2.124 \pm 0.033$ & $2.263 \pm 0.006$ & & $2.170 \pm 0.076^{\mathrm{a}}$ & \\
\hline $\mathrm{Fe}\left(\mathrm{H}_{2} \mathrm{O}\right)_{4}\left(\mathrm{SO}_{4}\right)^{+}$ & $2.075 \pm 0.030$ & $1.986 \pm 0.040$ & & $2.045 \pm 0.055$ & \\
\hline $\mathrm{Fe}\left(\mathrm{H}_{2} \mathrm{O}\right)_{2}\left(\mathrm{SO}_{4}\right)_{2}^{-}$ & $2.129 \pm 0.021$ & $2.029 \pm 0.035$ & & $2.063 \pm 0.059$ & \\
\hline Hydrolysis (dimeric species) & & & & & \\
\hline $\mathrm{Fe}\left(\mathrm{H}_{2} \mathrm{O}\right)_{5}-\mathrm{O}-\mathrm{Fe}\left(\mathrm{H}_{2} \mathrm{O}\right)_{5}{ }^{4+}$ & $2.089 \pm 0.059$ & & $1.831 \pm 0.001$ & $2.046 \pm 0.114$ & 3.495 \\
\hline Hydrolysis (trimeric species) & & & & & \\
\hline double corner $-\mathrm{Fe}_{3}\left(\mathrm{H}_{2} \mathrm{O}\right)_{10}(\mathrm{OH})_{4}{ }^{5+}$ & $2.064 \pm 0.014$ & $1.979 \pm 0.033$ & & $2.026 \pm 0.050$ & $\begin{array}{c}3.051 \\
3.595 \pm 0.008\end{array}$ \\
\hline Minerals & & & & & \\
\hline 'Periodic' ferrihydrite & & 2.052 & & & $2.941(1.2)^{\mathrm{d}}$ \\
\hline Octahedral Fe1 & & & $2.000 \pm 0.050^{\mathrm{b}}$ & & 3.017 (1.2) \\
\hline Octahedral Fe2 & & & $1.983 \pm 0.109$ & $1.997^{\mathrm{c}}$ & 3.137 (1.2) \\
\hline Tetrahedral Fe3 & & & $2.004 \pm 0.030$ & & $3.320(1.2)$ \\
\hline & & & & & $3.396(2.4)$ \\
\hline & & & & & $3.475(1.2)$ \\
\hline & & & & & $3.504(2.4)$ \\
\hline & & & & & $3.584(2.4)$ \\
\hline 'Periodic' schwertmannite & & & & $2.020 \pm 0.106$ & $3.004(2)$ \\
\hline & & & & & $3.280(1)$ \\
\hline & & & & & $3.388(1)$ \\
\hline & & & & & $3.607(1)$ \\
\hline & & & & & $3.668(1)$ \\
\hline
\end{tabular}

\footnotetext{
${ }^{\mathrm{a}}$ Includes the $\mathrm{Fe}-\mathrm{Cl}$ bonds.

${ }^{\mathrm{b}}$ Includes $\mathrm{Fe}-\mathrm{OH}$ bond.

${ }^{\mathrm{c}}$ Average based on contribution of $64 \% \mathrm{Fe} 1-\mathrm{O}$ bonds, $21 \% \mathrm{Fe} 2-\mathrm{O}$ bonds and $14 \% \mathrm{Fe} 3-\mathrm{O}$ bonds (i.e. $60 \% \mathrm{Fe} 1,20 \% \mathrm{Fe} 2$ and $20 \%$ $\mathrm{Fe} 3$ ).

${ }^{\mathrm{d}}$ Values in parentheses indicate average number of $\mathrm{Fe}$ atoms in this position based on $60 \% \mathrm{Fe} 1,20 \% \mathrm{Fe} 2$ and $20 \% \mathrm{Fe} 3$.
} 

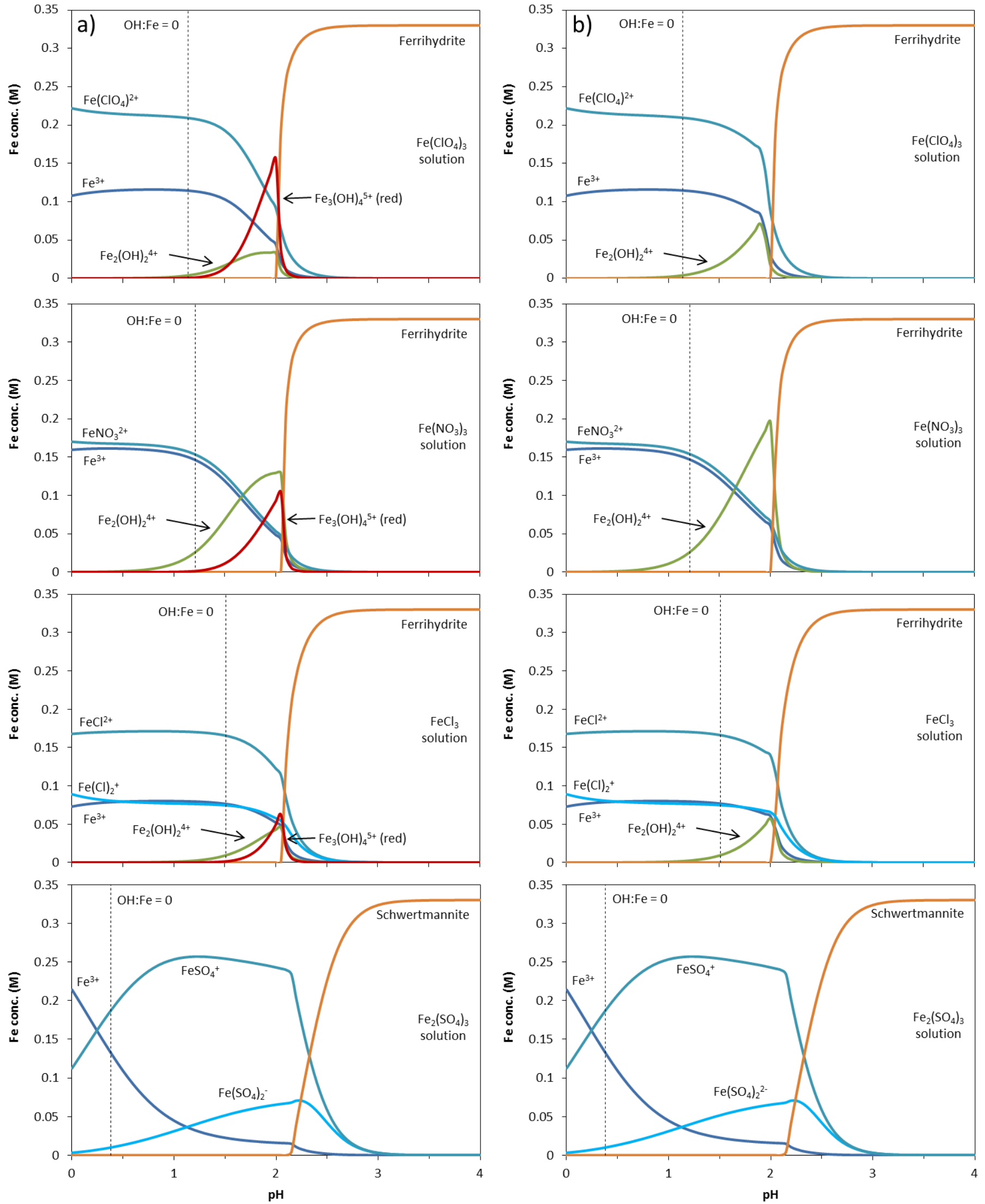

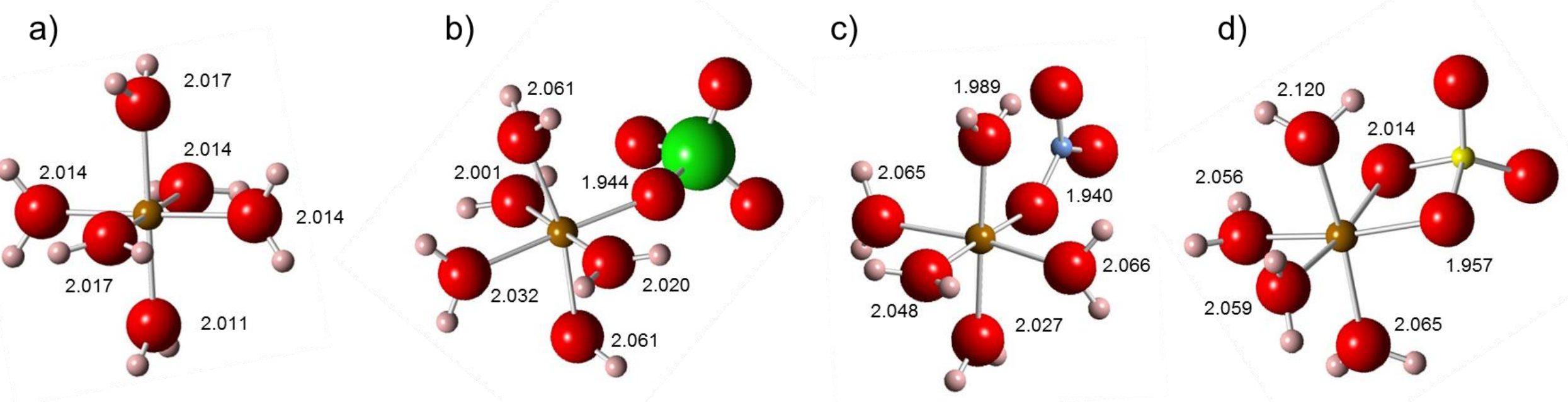

e)

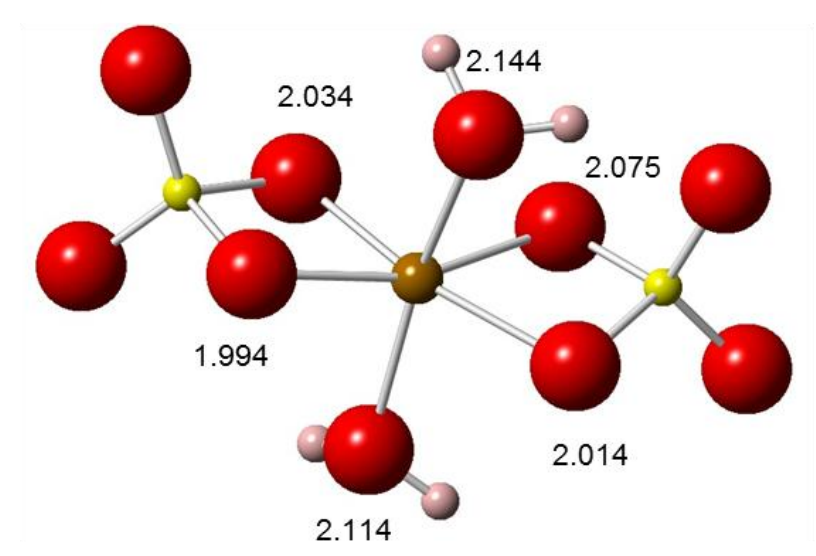

f)

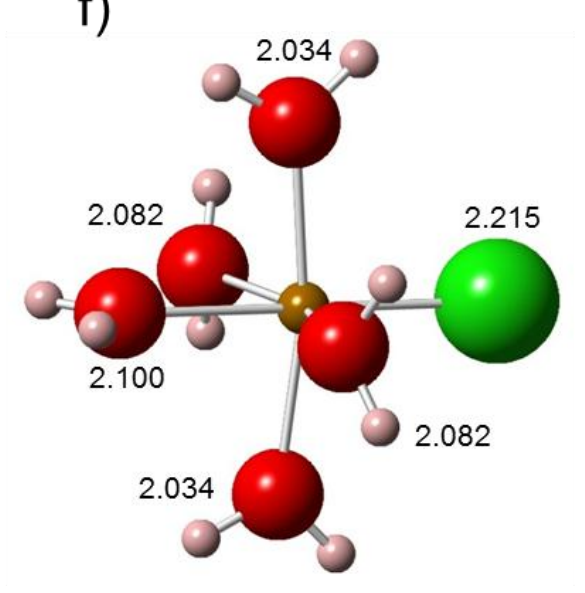

g)

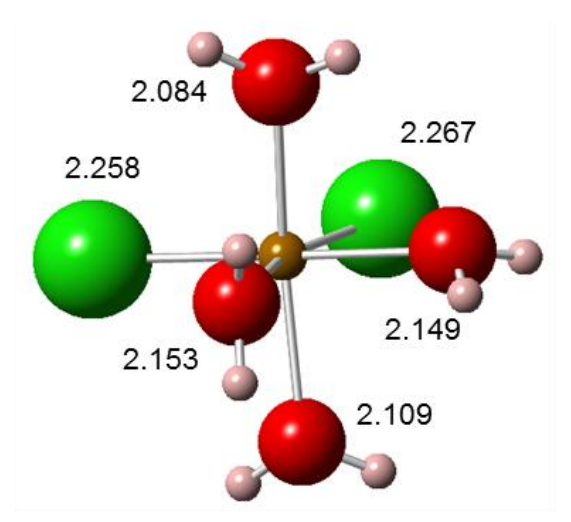


a)

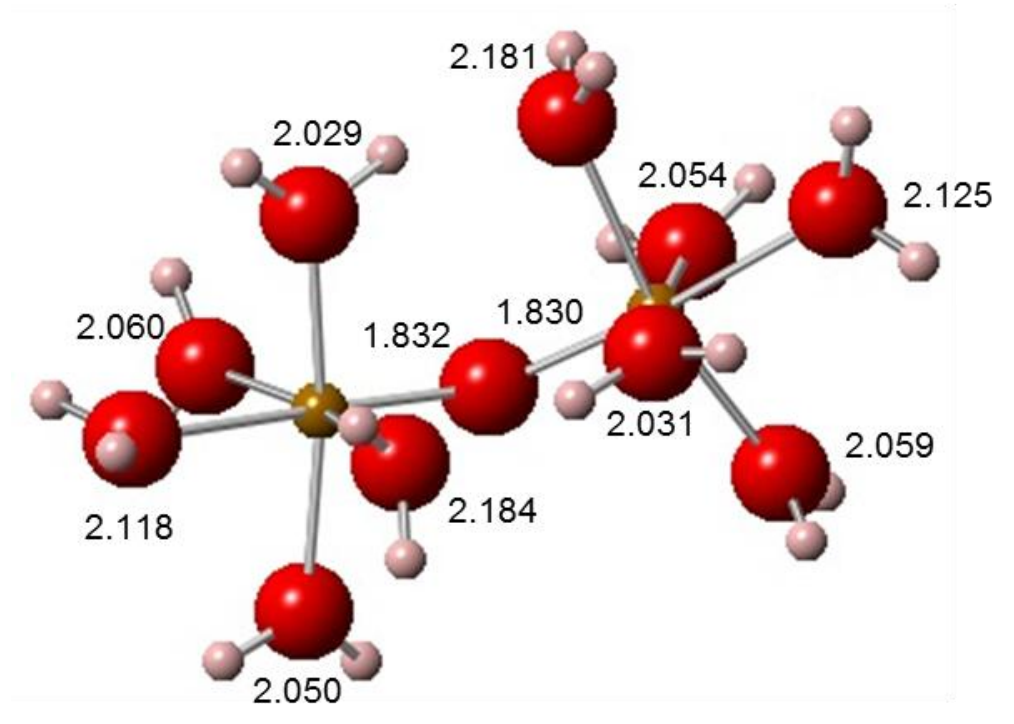

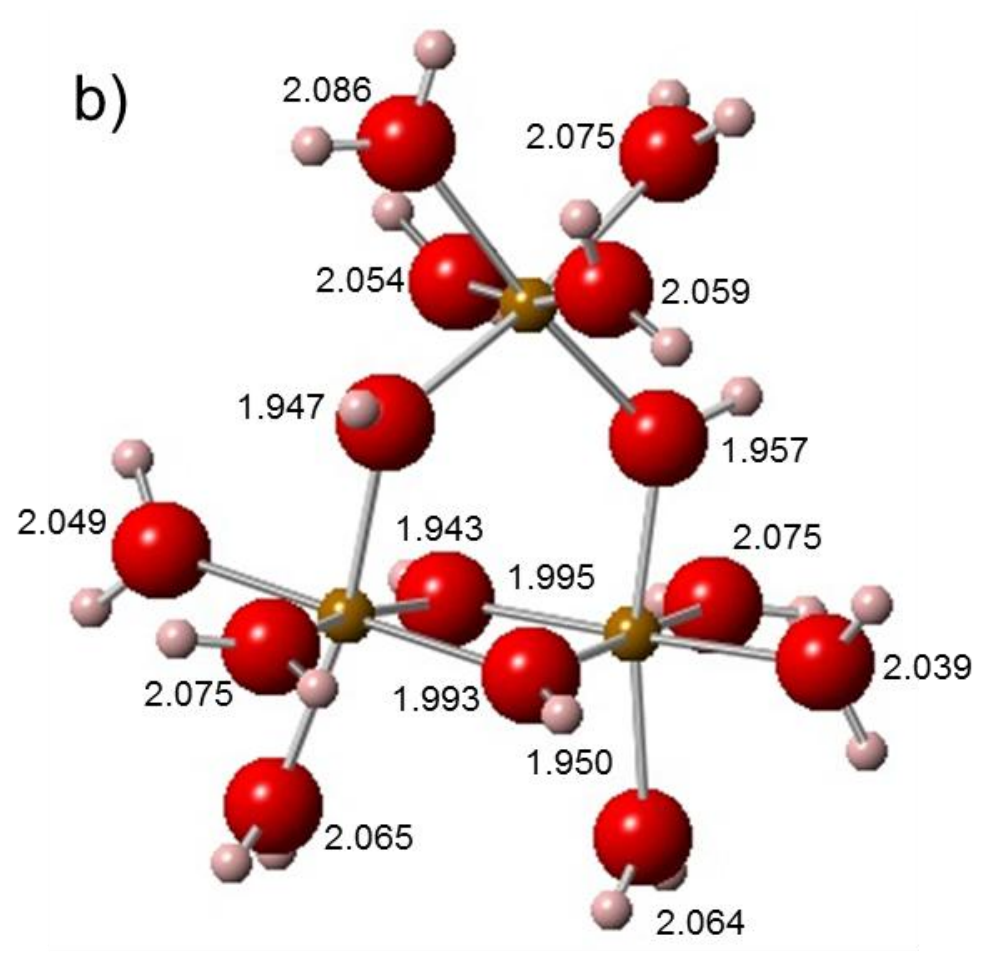




$$
\begin{aligned}
& h=\frac{d z}{d a} \\
& h=\frac{1}{A}
\end{aligned}
$$


Figure 5
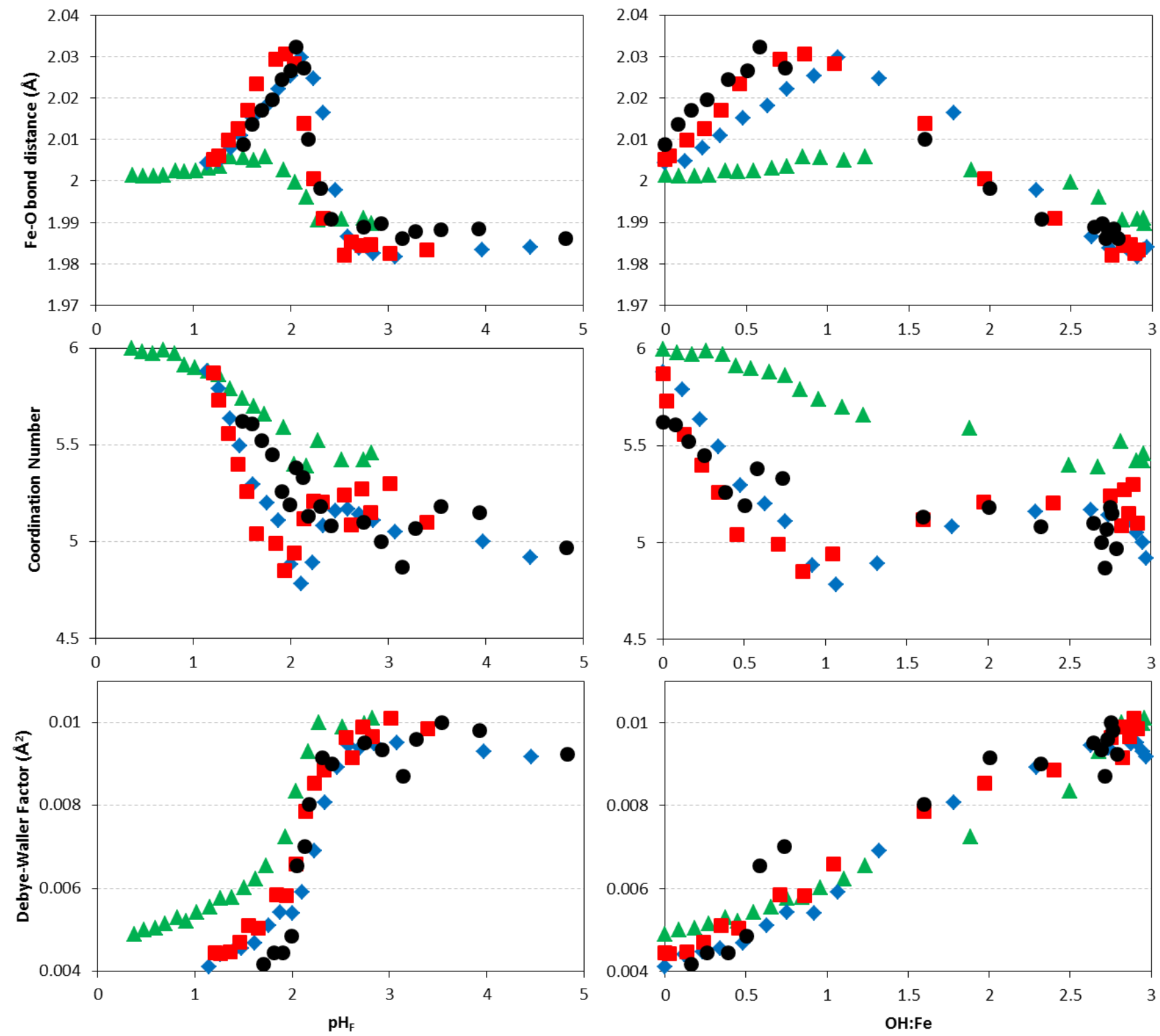
Figure 6
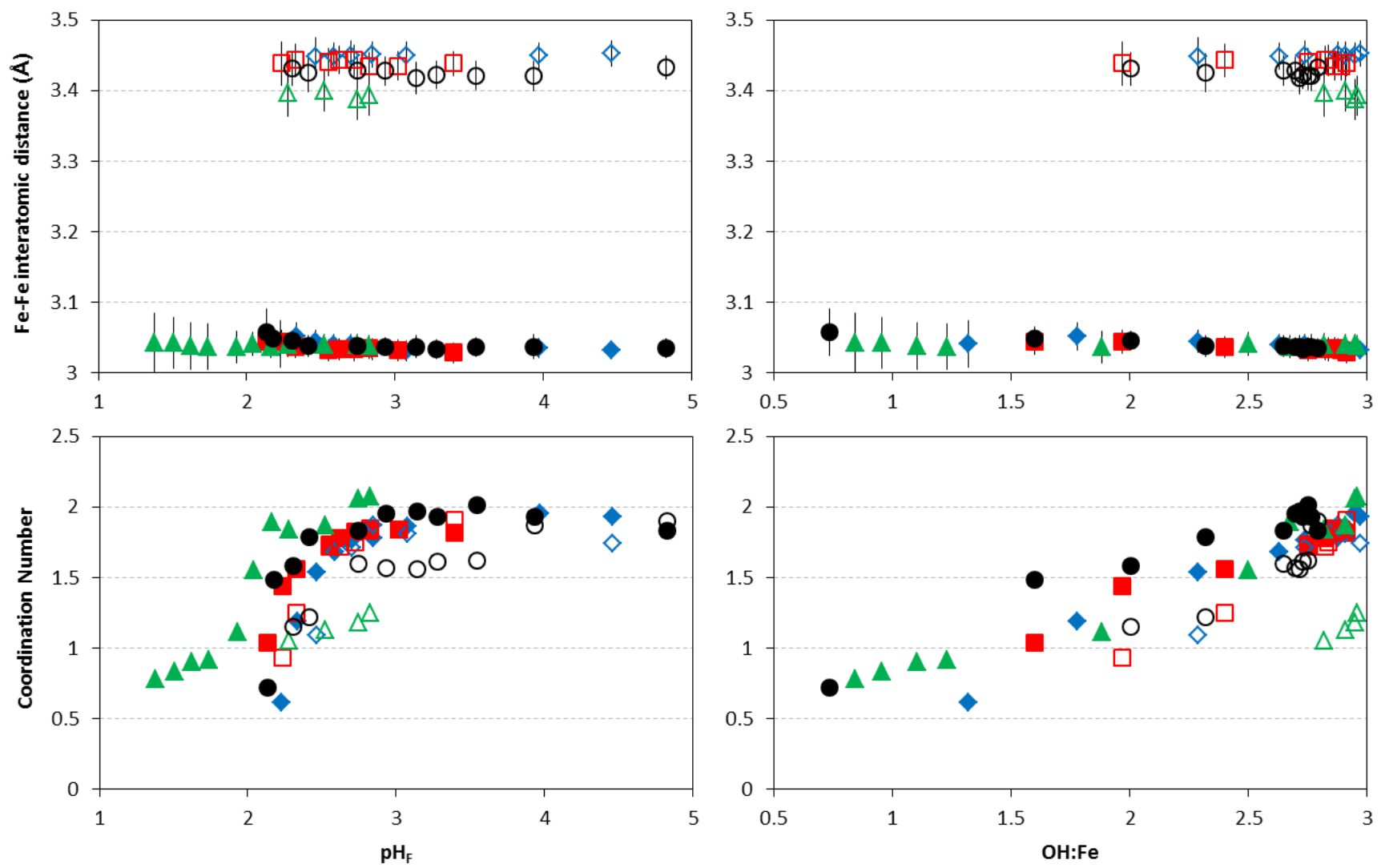


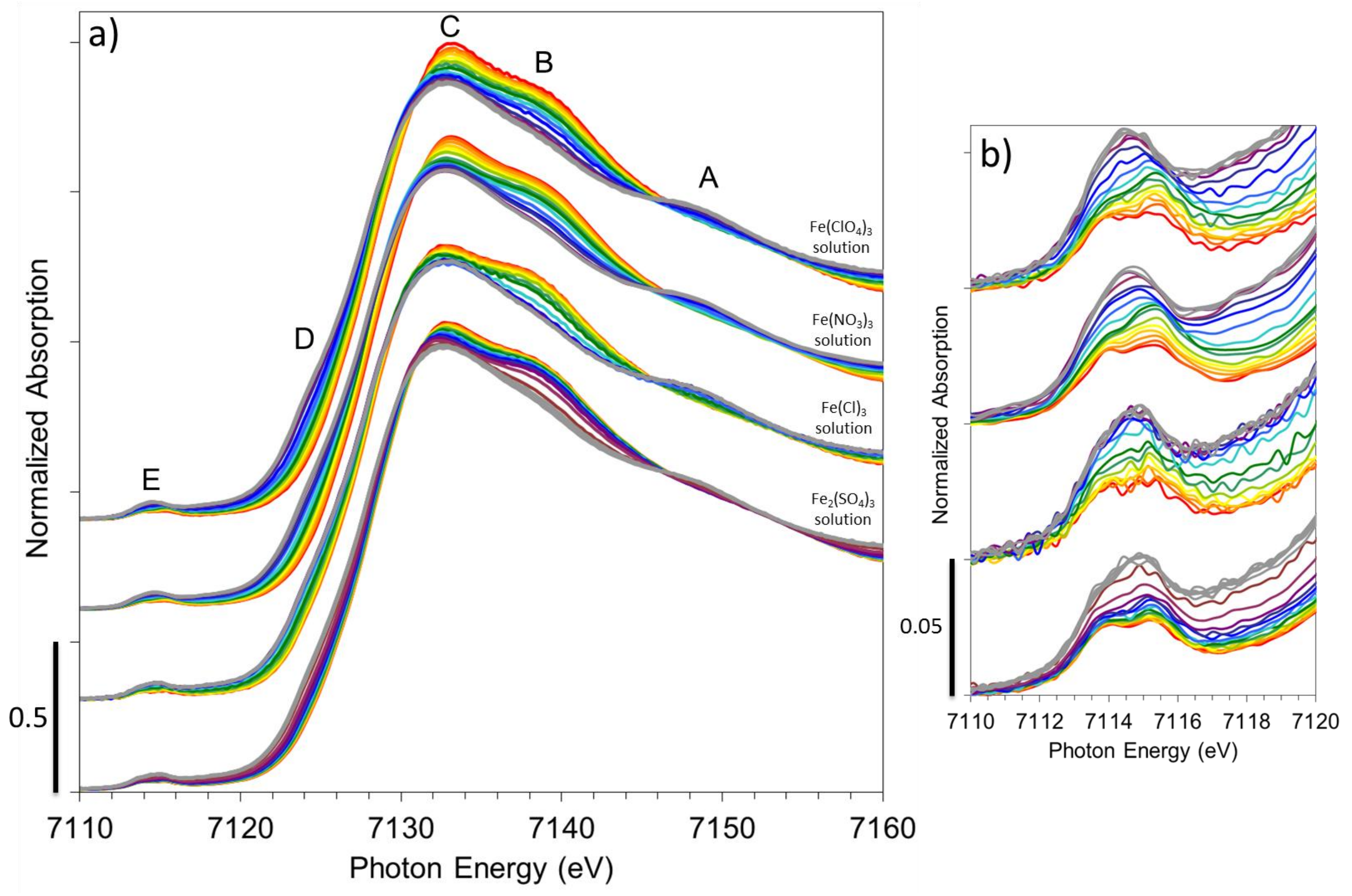



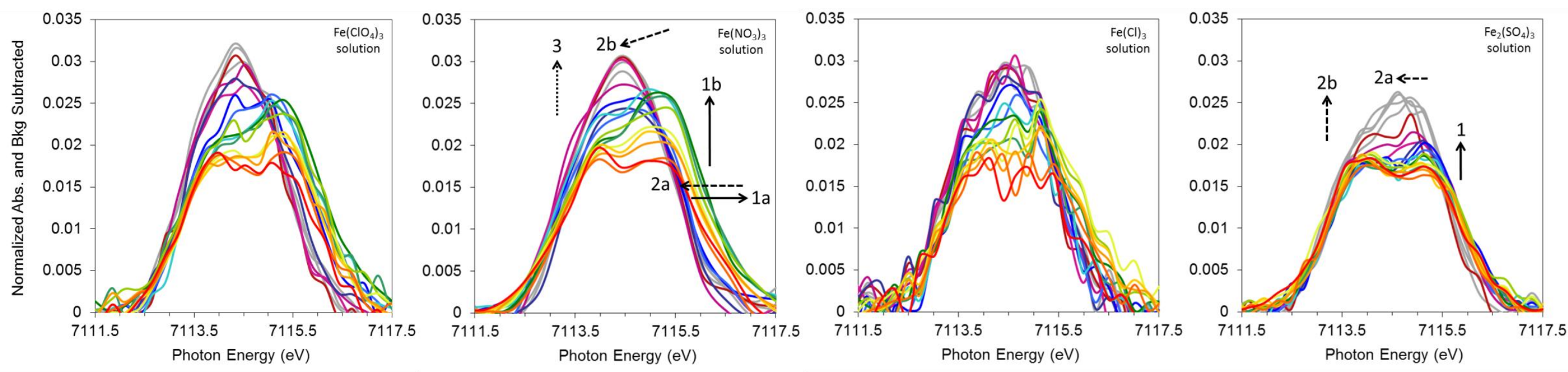